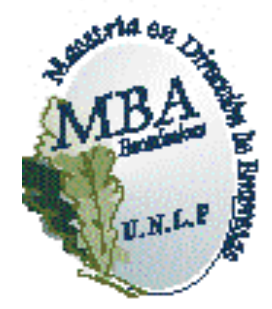

Universidad Nacional de La Plata

Facultad de Ciencias Económicas

MBA - Maestría en Dirección de Empresas

\title{
La vocación emprendedora del Contador Público
}

Análisis y comparación con otras profesiones universitarias

Trabajo final para optar al título de Magister

Autor: Cr. Javier Alejandro Mónaco

Directora: Mg. Gabriela Mollo Brisco

\author{
La Plata
}

$30 / 03 / 2017$ 


\section{Contenido}

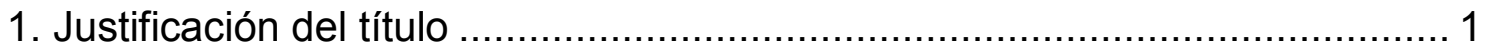

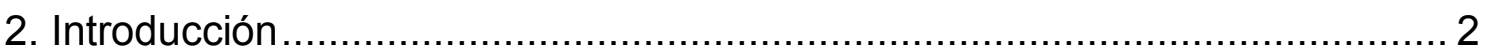

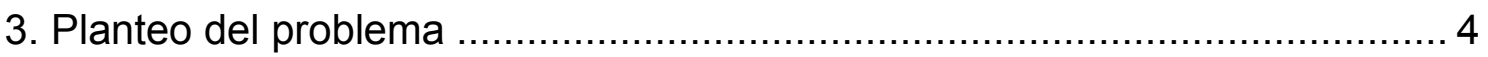

4. Objetivos de la investigación ................................................................. 5

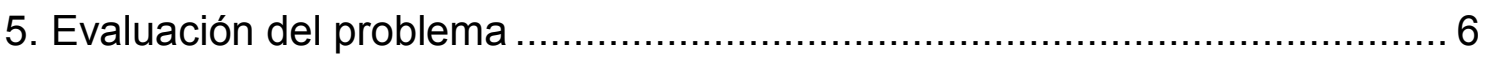

6. Alcance de la investigación .............................................................. 7

7. Marco teórico de referencia...................................................................... 7

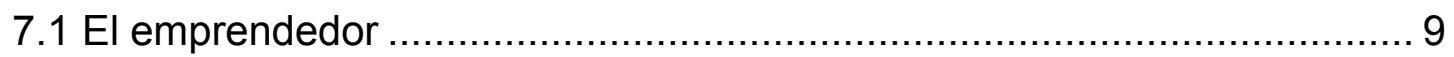

7.1.1 Concepto, origen y evolución ……............................................. 9

7.1.2 Enfoques y factores asociados .................................................. 11

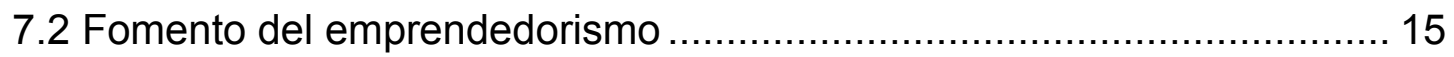

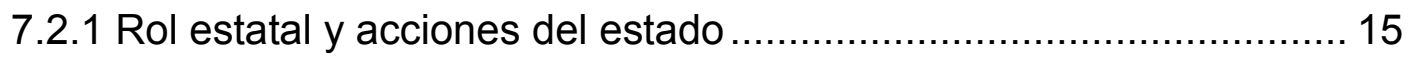

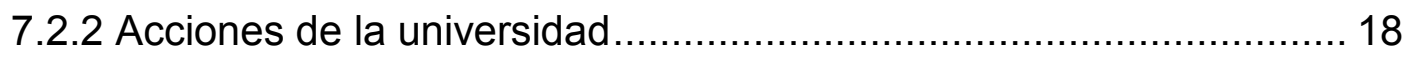

7.3 El contador y el emprendedorismo ………....................................... 19

7.3.1 Formación de base y aptitudes .................................................... 19

7.3.2 Competencias emprendedoras …................................................ 24

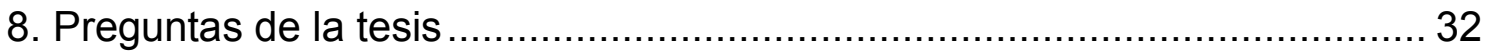

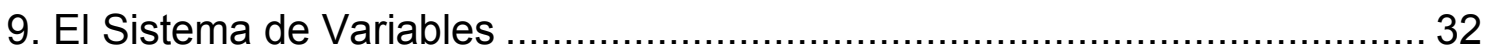

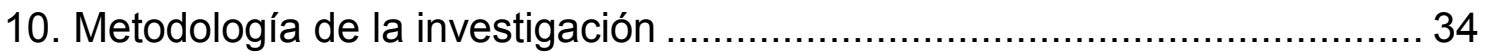

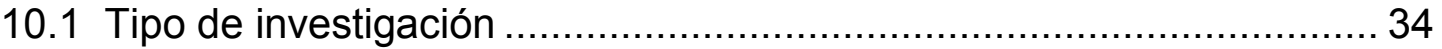

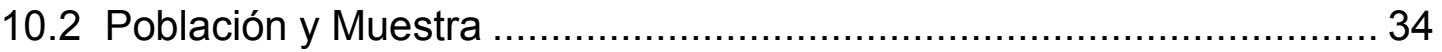

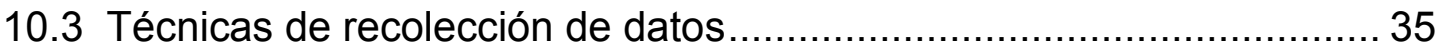

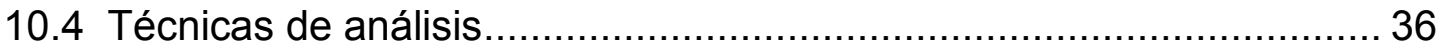

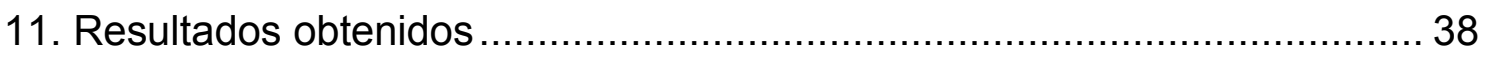


11.1 Análisis primario

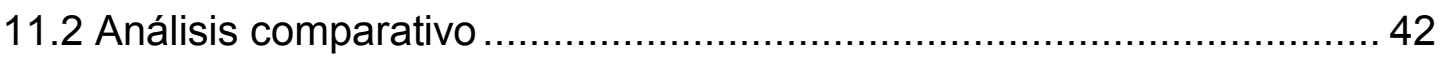

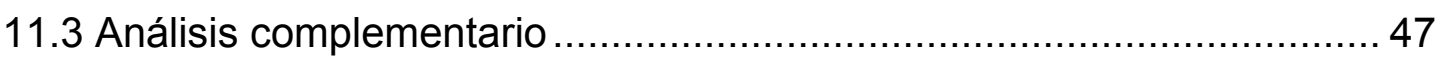

12. Conclusiones y respuestas a las preguntas de la tesis ........................ 49

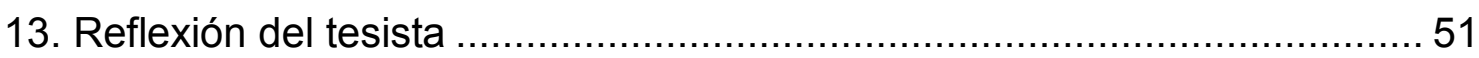

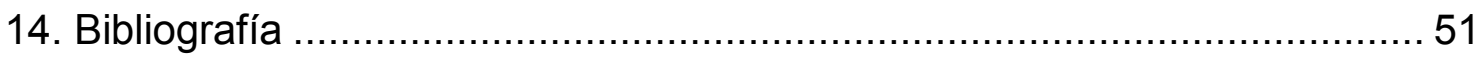

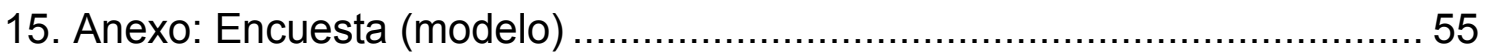




\section{Justificación del título}

Previo a toda introducción, merece la pena la digresión terminológica acerca del uso del vocablo "vocación" (emprendedora) en el título de la tesis, en la medida en que se podrían haber utilizado palabras similares como "Cultura emprendedora", "Espíritu emprendedor" ${ }^{\prime 1}$ o cualquier otra frase que identifique el acercamiento y predisposición de las personas (en especial de los contadores) al desarrollo de empresas nuevas, lo que es decir, un apego o interés al emprendedorismo ${ }^{2}$.

En tal sentido, se eligió la palabra vocación, por el sentir y resumir en esa expresión, como la "Inclinación o interés que una persona siente en su interior para dedicarse a una determinada forma de vida o un determinado trabajo"3. También, a nivel general, la vocación aparece relacionada con los anhelos y con aquello que resulta inspirador para cada sujeto. Se supone que la vocación concuerda con los gustos, los intereses y las aptitudes de la persona. La vocación está relacionada al sacrificio, a la predisposición y al tener que renunciar en determinadas oportunidades a otras actividades recurrentes de la vida profesional, como es en este caso.

De hecho, gran parte de las preguntas que son parte de la encuesta comienzan con la frase "siente usted que..." o "usted se considera..." o bien "cree usted que...", lo que se centra más en la autopercepción de lo que es uno mismo, más que en las características reales que pueda ostentar cada caso analizado.

\footnotetext{
${ }^{1}$ La escuela de Ingeniería de Antioquía (Medellín), fusiona ambos conceptos, y define al espíritu emprendedor como "el impulso de la cultura del emprendimiento dirigido a formar una mentalidad de innovación permanente en sus quehaceres y en la empresa". (Galindo \& Echavarría, 2011)

${ }^{2}$ Se encontró en mayor medida la palabra emprendedurismo y en menos ocasiones la palabra emprendedorismo, siendo que la primera, si bien de uso cotidiano, no se encuentra en diccionarios de neologismos, mientras que la segunda, si bien no se encontró al momento, pareciera ser la estructura óptima de la palabra en su afán de ser traducida del término madre en francés, derivado al inglés. La búsqueda en el diccionario digital de la Real Academia Española, cuando se buscó "emprendedorismo", llevó a buscar por asociación a emprendedor/a, y para el caso del "emprendedurismo", no hace referencia a otra palabra o familia de palabras

${ }^{3}$ Oxford Living Dictionaries en es.oxforddictionaries.com
} 
Si bien el título puede inducir a que los contadores podrían ser los principales interesados por los resultados y conclusiones de esta tesis, se deja aclarado que la utilidad de la investigación, agregará valor a las instituciones educativas de grado de otras profesiones, a las de las ciencias económicas en particular, a las instituciones de posgrado orientadas a la gestión (MBA), a los docentes que quieran incursionar en la capacitación en competencias de emprendedores, a los estudiantes de carreras afines a la gestión de recursos, y en especial, al tesista como corolario de la asistencia al curso, la aprobación de las materias, y tiempo después, de encontrar la temática que permita atravesar transversalmente varias asignaturas de dicha maestría.

\section{Introducción}

Existe amplio consenso que las profesiones universitarias son un componente importante en el conjunto de elementos y actores que conforman el esquema de desarrollo de una sociedad. Esto es así, porque la evolución en el conocimiento, sobre todo académico y científico, tiene implicancias en el nuevo paradigma de lo que se llama desarrollo, ya no en términos económicos, sino en aspectos vinculados a la educación, la salud, la expectativa de vida y la vida digna, tal como lo define el Programa de las Naciones Unidas para el Desarrollo (PNUD).

La formación de grado, es uno de los impulsores de los índices de desarrollo humano (IDH), que considera que el nivel alcanzado de la población en su educación puede tener implicancias directas sobre el avance económico de un país, o región. Ello, va a depender de la capacidad de generar un bienestar no solamente en la persona, sino también en qué medida se generan externalidades positivas en el resto de la población.

A su vez, el factor educación suele ser, en los países en desarrollo, uno de los componentes más determinantes en los modelos de competitividad de la matriz productiva, no solamente en la industria pesada a nivel operacional, sino 
también en las denominadas industrias "blandas" en cuanto a la generación de conocimiento que se traduzca en valor agregado tecnológico. La cantidad y calidad de profesionales, van a garantizar el desarrollo en todos sus términos, cuando fácticamente se vuelquen los conocimientos a la generación de riqueza regional, redistribución de ingreso, reasignar recursos y generar empleo entre otros factores de desarrollo.

En síntesis, se buscará estudiar la vocación emprendedora del contador público, en cuanto, a priori, posee un amplio espectro en formación vinculada a la gestión de los negocios, y verificar en qué medida se vuelcan al desarrollo de emprendimientos propios como complemento o sucedáneo para su medio de vida.

Esta tesis de investigación se dividirá en tres apartados:

1) El primero, estará destinado a la definición de la problemática, objetivos de la tesis, metodología utilizada y el alcance de la investigación. Es decir, la justificación del problema y de qué manera se propone arribar a los resultados (e interpretaciones de los mismos) que dan respuesta a las preguntas de tesis.

2) En el segundo se desarrollará el marco teórico desde el inicio del concepto del emprendedorismo hasta la actualidad, el impulso social mediante las acciones del estado y las universidades, y concluyendo en las competencias necesarias del emprendedor. Este marco teórico, ayudará a entender la conexión y coexistencia en una misma persona del emprendedor y el profesional, con sus similitudes y diferencias en cuanto a su formación y sus condiciones internas.

3) Finalmente, se mostrarán resultados de la investigación realizada y conclusiones arribadas en relación a la educación emprendedora y cultura emprendedora del profesional. Los análisis realizados se dividen en un análisis primario, en el cual se involucra al contador público; un 
análisis comparativo, donde se contrasta dicha profesión con otras profesiones universitarias; y por último un análisis complementario, donde se analizan a los profesionales en general, involucrando contadores y no contadores.

Estos resultados, pretenden brindar otra perspectiva hacia lo que se podría llamar en el futuro una reconversión de la profesión contable, tanto en su etapa de formación de grado, como también la base para la articulación en el esquema de creación de empresas de una sociedad.

\section{Planteo del problema}

El ejercicio profesional del contador, según se establece en la Ley de Ejercicio Profesional 10.620, se entiende como "...todo acto realizado en forma personal, que suponga los conocimientos propios de las personas con diplomas comprendidas en la presente Ley" y luego de ello hace una mención taxativa de actividades, pero no limitativa en cuanto a la emisión de informes, dictámenes y asesoramiento.

Sin embargo, el abordaje que se pretende establecer para este trabajo, es el del ejercicio profesional en cuanto a la práctica de las habilidades adquiridas por el contador, ya no como asesor ni como emisor de dictámenes, sino como gestor de negocios, innovador, emprendedor o cualquier otra calificación que lo vincule a la aplicación de los conocimientos para crear nuevas empresas.

En lo que particularmente involucra al planteo del problema, se enfoca en responder a preguntas que surgen del tesista, tras haber atravesado más de una década en el desarrollo de la profesión y del ejercicio de la docencia universitaria. Estas preguntas nacen de la reflexión permanente acerca por qué merece la pena estudiar el acercamiento al mundo de los negocios del profesional en ciencias económicas. Este planteo, se podrá resumir con las siguientes preguntas: 
- ¿Cuál es la proporción de contadores con vocación emprendedora?

- ¿Consideran los contadores que han recibido formación emprendedora en su formación de grado? y ¿en qué forma intentan complementarla?

- ¿Cuenta el contador con las competencias básicas requeridas para la formación de una cultura emprendedora?

- ¿Poseen los contadores públicos una mayor vocación emprendedora que el resto de los profesionales universitarios?

Los resultados de esta tesis se espera que brinden una respuesta a estas preguntas, y además, establezcan resultados próximos que ayuden a construir un perfil emprendedor entre los profesionales de las ciencias económicas, aprovechando por parte de ellos, no solamente los conocimientos académicos adquiridos, sino las oportunidades que el marco de los negocios brinda a estos profesionales por la proximidad al desarrollo de los mismos.

Estas conclusiones, basadas en la metodología de la investigación y el marco teórico, podrán utilizarse para un estudio de mayor diversidad con otras profesiones liberales de las ciencias económicas (Licenciado en Administración o Licenciado en Economía), e incluso con la vocación emprendedora de otras profesiones independientes.

\section{Objetivos de la investigación}

Objetivo general:

El principal objetivo es determinar si existe una mayor vocación emprendedora en los contadores públicos de Facultad de Ciencias Económicas de la Universidad Nacional de La Plata, con respecto al resto de las profesiones universitarias y cuáles son los factores que impulsan su desarrollo. 
Objetivos específicos:

- Identificar si el desarrollo de competencias instrumentales (de formación) del contador, prevalecen por sobre las actitudinales en su incidencia en la vocación emprendedora.

- Determinar si los profesionales consideran desarrolladas sus habilidades emprendedoras y en qué medida la complementan de manera extracurricular.

- Establecer si la postura adversa al riesgo es una limitante para el contador para el desarrollo de una actitud emprendedora con respecto a otras profesiones.

- Convenir si otros factores como la, edad, años de profesión o género, inciden en la vocación emprendedora del profesional.

Dichos objetivos serán planteados como preguntas de la tesis en el apartado 8.

\section{Evaluación del problema}

La importancia del estudio de esta problemática radica principalmente en que es significativo comprender que ante un contexto cambiante, inestable y vertiginoso desde el punto de vista del marco de desarrollo de los negocios, los profesionales deben sacar a la luz todo el herramental que un profesional asesor tiene en su cúmulo de conocimientos y entender que hoy por hoy, la sociedad demanda nuevas competencias, desplazando al viejo concepto incumbencias profesionales. ${ }^{4}$

El autoempleo no solamente es una figura asociada al micro empresario, sino que también es una forma de desarrollar la profesión, en la media en que dicho estudio profesional no puede funcionar de manera organizada como entidad independiente a la persona del profesional. Este concepto de autoempleo, si bien es tomado por cierta bibliografía como una instancia a superar, en general,

\footnotetext{
${ }^{4}$ Ya la Ley de Educación Superior 24.521 de 1995, deja de mencionar al concepto de incumbencias profesionales, pasando al de "adquisición de conocimientos y competencias" (art. 19 L.E.S.) o "Los conocimientos y capacidades que tales títulos certifican, así como las actividades para las que tienen competencia sus poseedores, serán fijados y dados a conocer por las instituciones universitarias..." (art. 42 L.E.S.)
} 
es tomado por las universidades y los organismos estatales, como un instrumento de movilidad social, una alternativa para disminuir el desempleo, y la recomposición regional de las ciudades afectadas especialmente por el cierre de industrias.

El estudio de la figura del emprendedor, contribuye además, a situar al profesional ante un abanico de oportunidades de nuevos negocios que las redes de contactos puedan generar como alternativa al autoempleo.

\section{Alcance de la investigación}

La investigación tendrá como alcance una muestra de contadores graduados de la Facultad de Ciencias Económicas de la Universidad Nacional de La Plata (estén estos matriculados o no) y profesionales independientes de otras carreras de grado universitario de 5 o más años.

\section{Marco teórico de referencia}

Lo que se pretende estudiar es en qué medida existe dentro del entorno de la cultura emprendedora, una vocación específica por parte de los contadores públicos. En la ilustración 1 se plantea el esquema del marco teórico que se desarrollará en este apartado.

Ilustración $N^{0}$ 1: Esquema resumen del marco teórico de referencia

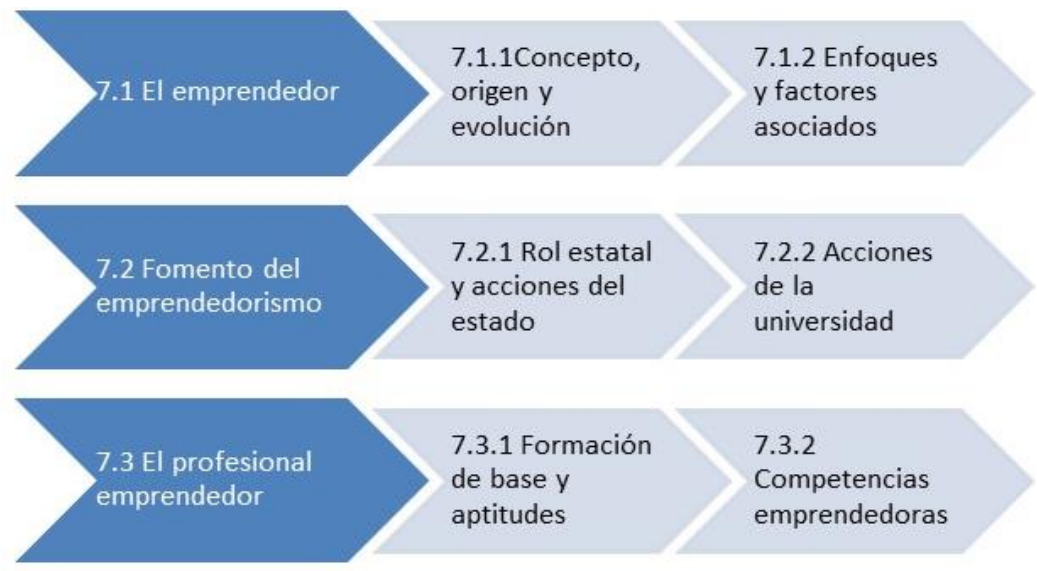

Fuente: Elaboración Propia 
Antecedentes de la Investigación.

Se han encontrado trabajos de investigación, muy concisos y contundentes, que estudian, si bien de manera fragmentada y parcial, cuestiones vinculadas a:

- Los graduados universitarios y la generación de emprendimientos innovadores. (Gennero de Rearte, Liseras, Graña, \& Baltar, 2006)

- Diagnóstico de la cultura emprendedora en la escuela de ingeniería de Antioquía (Galindo \& Echavarría, 2011, págs. 85-94)

- Factores asociados a la vocación emprendedora de alumnos universitarios (Liseras, Gennero de Rearte, \& Graña, 2003)

- Emprendorismo en el ámbito universitario. (Cabello Diaz, 2005)

A su vez, existen antecedentes de trabajos que estudian la formación emprendedora en los alumnos:

- Formación en emprendimiento en la carrera de administración de empresas de la Universidad de Popayán (Correa Correa, Delgado Hurtado, \& Conde Cardona, 2005)

- Perfil y prácticas educativas del docente orientado a la innovación en las escuelas de negocio de México (Verástegui \& Farías Martinez, 2012)

- Perfil docente y fomento de la cultura del emprendimiento: búsqueda de una relación (Pertuz Peralta, Rojas Caicedo, Navarro Rodriguez, \& Quintero, 2015)

Todos estos trabajos enfocados en la formación de profesionales en su cultura emprendedora, como aquellos centrados en la etapa de formación universitaria, son tomados en cuenta para los análisis comparativos y complementarios de las conclusiones arribadas. 


\subsection{El emprendedor}

\subsubsection{Concepto, origen y evolución}

La palabra emprendedor, proviene del francés "entrepreneur" ${ }^{\text {, }}$ que significa pionero, y se refiere a la capacidad de una persona de realizar un esfuerzo adicional para alcanzar una meta o iniciar una nueva empresa o proyecto .Este término se atribuye también a aquellos individuos que son innovadores o agregan valor a un producto o servicio ya existente (Fernandez Salinero \& de la Riva, 2014). Este vocablo fue introducido en la literatura económica por primera vez en los inicios del siglo XVIII por el economista francés Richard Cantillon con un aporte relevante para comenzar a comprender el concepto de emprendedor y el rol que juega el emprendimiento en la economía.

En 1804, el economista francés Jean-Baptiste Say, hizo un interesante aporte a la definición de Cantillon, afirmando que el "entrepreneur" es un individuo líder, previsor, que asume riesgos y evalúa proyectos, y que moviliza recursos desde una zona de bajo rendimiento a una zona de alta productividad. Say, rescata el hecho de que el éxito emprendedor no sólo es importante para un individuo, sino también para toda la sociedad.

El británico John Stuart Mill, en 1848, enfatizó más la importancia del emprendimiento para el crecimiento económico. Este autor expresó que "el desarrollo del entrepreneurship requiere de habilidades no comunes" y lamentó la inexistencia de una palabra en el idioma inglés con el mismo significado que el término "entrepreneur" en francés.

Posteriormente Joseph Schumpeter (1911) retoma la línea de estudio de Say, evaluando la importancia de la persona emprendedora pero desde el planteamiento de la existencia del desequilibrio dinámico causado por el empresariado innovador. Schumpeter considera a este último como un agente

\footnotetext{
${ }^{5}$ Etimológicamente proviene de "in" y "prenderé". En inglés se utilizan los términos undertaker y adventurer como sinónimos, reemplazados luego por el vocablo inglés "entrepreneurship" 
activo y creador que hace que la economía no permanezca en equilibrio, ya que no se adapta a las circunstancias del mundo exterior sino que las cambia.

Frank Knight, en 1921, plantea su concepto centrándose en el estudio de las capacidades que poseen los emprendedores para los negocios y estableciendo que su éxito depende de tres elementos principalmente: capacidad, esfuerzo y suerte. En la línea de Knight se sitúa Ludwig Von Mises en 1949, quien identifica tres características que considera esenciales para que un individuo sea considerado emprendedor. La primera lo define como un evaluador, la segunda característica es la de empresario, y la tercera considera que el emprendedor "soporta" la incertidumbre, ya que actúa en función del futuro y no conoce exactamente las acciones que otros seres humanos llevarán a cabo.

Ilustración № 2: Evolución histórica y sus autores
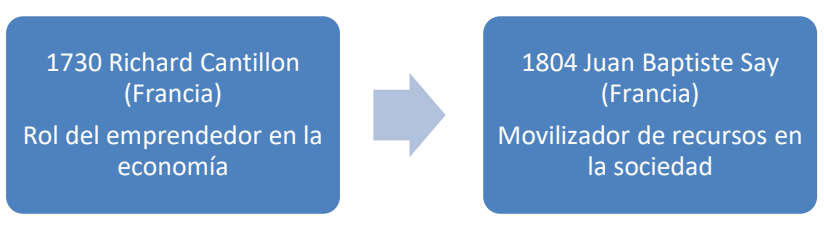

1949 Ludwig Von Mises (Ucrania-USA)

Evaluador e incertidumbre

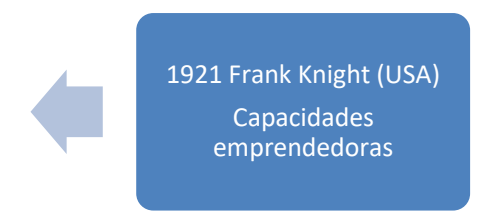

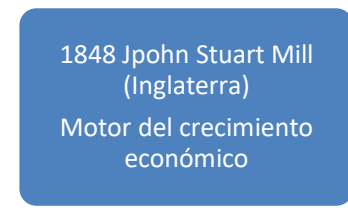

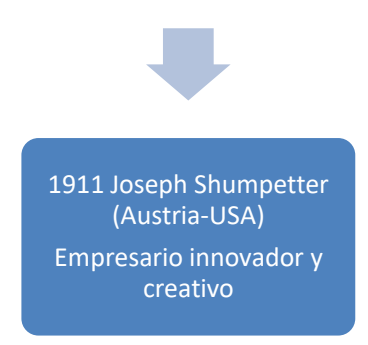

Fuente: Elaboración Propia 
El emprendimiento es, en consecuencia, un modo de pensar, razonar y actuar centrada fundamentalmente en las oportunidades (aunque en ocasiones también en las necesidades ${ }^{6}$ ) planteada con visión global y llevada a cabo mediante un liderazgo equilibrado y la gestión de un riesgo calculado. Su resultado es la creación de valor que beneficia a la empresa, a la economía y a la sociedad.

\subsubsection{Enfoques y factores asociados}

Siendo sintético en las clasificaciones, se pueden destacar dos enfoques teóricos acerca de cómo la influencia del entorno actúa sobre el emprendedor y la otra que se refiere a factores individuales.

Las primeras las podemos incluir en la denominada Escuela Ambiental, siendo que esta escuela de pensamiento viene caracterizada por centrarse en los factores del entorno como elementos explicativos del rendimiento del emprendedor, así como en las redes de interacciones en las que se encuentra inmerso.

Un autor que se puede considerar un precursor de esta escuela es Schumpeter (1934/2004), quien sostiene que la persona emprendedora es aquella que con sus actividades genera inestabilidades en los mercados. Para este autor, el emprendimiento es un rasgo de comportamiento que tiene que ver con promover cambios en el entorno y las habilidades emprendedoras se aprenden, no son características poseídas necesariamente por el individuo. E emprendedor persigue la oportunidad (Baumol, 1990), se compromete rápidamente, está predispuesto al cambio y se responsabiliza ante diferentes escenarios (Stevenson, 2000). Este planteamiento pone el énfasis en el mercado y sus condiciones como agentes promotores del emprendimiento. En

\footnotetext{
${ }^{6}$ Los informes anuales del GEM (Global Entrepreneurship Monitor), suelen diferenciar mediante índices, aquellos emprendedores motivados en la necesidad y en la oportunidad. Es decir, aquellos que deben resolver un problema generalmente de tipo financiero con aquellos que el mercado ofrece una expectativa de crecimiento del mercado. Reporte anual 2015-2016 del GEM en http://gemconsortium.org/report.
} 
este caso se requieren unas cualidades especiales en la figura del emprendedor, pero mediatizadas por el entorno y que pueden adquirirse a través del aprendizaje (Fernandez Salinero \& de la Riva, 2014).

La segunda es conocida como Escuela Psicológica. Esta corriente se ha centrado principalmente en encontrar los rasgos personales que son compartidos por los emprendedores de éxito, cuya personalidad puede describirse por medio de un patrón específico de características relacionadas con la acción.

Esta última escuela considera a la persona emprendedora como aquella con capacidad de identificar oportunidades en los mercados a través de un proceso de descubrimiento. En este sentido, las características de los individuos en un contexto económico determinado, y que están relacionadas con el éxito emprendedor, son poseídas por la persona emprendedora y pueden optimizarse a través de la educación.

Dentro de esta escuela se puede citar a autores de la escuela austriaca como Von Mises (1949/1996) o Kirzner (1973), quienes consideran que la competencia emprendedora responde a cualquier tipo de actividad que genere incertidumbre, y consideran a la persona emprendedora como aquella con capacidad de identificar oportunidades en los mercados a través de un proceso de descubrimiento. En este sentido, las características de los individuos en un contexto económico determinado están relacionadas con el éxito emprendedor, son poseídas por la persona emprendedora y pueden optimizarse a través de la educación, pero es necesario que ya formen parte de la personalidad emprendedora. (Fernandez Salinero \& de la Riva, 2014)

En Estados Unidos, existe una tendencia más marcada hacia la escuela de corte ambientalista, heredera de las ideas de Schumpeter, mientras que en Europa, la tendencia parece estar orientada a la escuela austríaca de carácter más psicológico. Independientemente de las razones relacionadas con la personalidad y la cultura, parecen existir unas características comunes que 
definen una personalidad emprendedora. Sin embargo, actualmente, se aceptan las dos teorías como expresiones de emprendimiento, pero cada vez tiene mayor aceptación la coexistencia de ambas corrientes como determinantes del emprendedor.

Los aspectos vinculados específicamente a la vocación emprendedora, pueden clasificarse en cuanto a factores que perfilan al individuo hacia la creación de su propia empresa, tal como lo hacen Graña y Liseras (2005), donde se mencionan determinados elementos vinculados. En el siguiente esquema, se resumen los componentes afines a la vocación emprendedora, los cuales se desarrollaran a continuación.

Ilustración $\mathrm{N}^{\circ}$ 3: Elementos vinculados a la acción emprendedora

Factores de

desplazamiento

(positivo y

negativo)
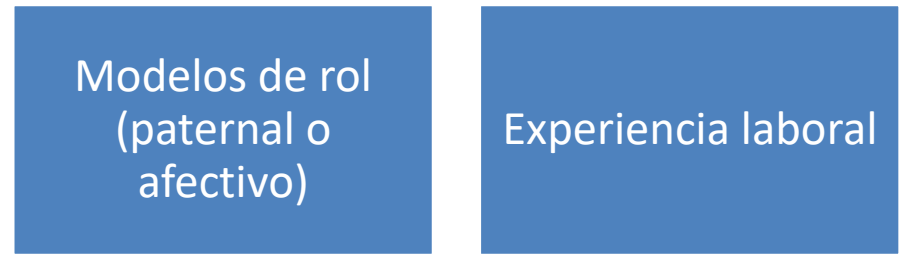

\section{Nivel educativo y \\ educación \\ empresaria}

Percepción de

ingresos relativos

Fuente: elaboración propia

Shapero (1978), conceptualiza al desplazamiento como el pasaje de una situación de estabilidad hacia la acción, siendo numerosas las causas por las cuales puede lograrse ese desplazamiento. Una forma de clasificar a dichos factores de desplazamiento es mediante el desplazamiento positivo, es decir, aquellos que provienen de la existencia de una nueva oportunidad de mercado, ya sea porque existen necesidades de mercado insatisfechas, o bien, aquella que provienen del crecimiento de un sector de la economía, por el auge de un producto o servicio. Es decir, que mediante una forma u otra, el emprendedor recibe señales del mercado. 
El desplazamiento negativo, por su parte, puede provenir del cambio en la vida familiar o laboral, el hecho de perder el trabajo, las necesidades de incrementar los ingresos por ampliación de la familia o separación, o cualquier otra condición, que lleve al trabajador a abandonar su empleo, (insatisfacción, decepción, precariedad laboral).

En cualquiera de los dos casos, según se ha estudiado (Katz, 1992), tanto la historia personal como el contexto social del individuo, ejercen una gran influencia en el modelo de creación de empresas, siendo que el modelo de padres es el más frecuente, dado que los progenitores influyen en el emprendedor desde la niñez en sus accionares emprendedores, como también de familiares y amigos cercanos, con tal vez menor influencia por el transcurso del tiempo, pero si por afinidad o empatía.

El trabajo en empresas familiares emprendedoras desde la infancia, como la alta presencia de modelos emprendedores en la localización geográfica cercana, actúan a su vez como modelos de rol a imitar. Cabe considerar al respecto, que no solamente la imitación proviene del modelo de rol, sino que en ciertas circunstancias, se trata de no imitar experiencias cercanas o de familiares, lo que hace incursionar en el emprendimiento.

En el libro "Padre rico-padre pobre" (Kiyosaki, 2003), que se destacó como best seller entre los libros de autoayuda orientados a los negocios, se narra la historia del autor, que cuenta con un padre biológico que le advierte acerca de las bondades de estudiar para obtener un empleo y asegurarse un empleo, mientras que una especie de padre postizo, le inculca las ventajas de pasar del empleo, hacia el autoempleo y luego al rol empresario, como medio de vida alternativo basado en la educación financiera ${ }^{7}$, dejando como corolario de la lectura, la importancia de la educación financiera en las personas, como parte de la formación adicional a la educación formal.

\footnotetext{
$7 \mathrm{Si}$ bien el libro citado no se puede considerar de contenido netamente académico, es destacable la influencia de dicho autor sobre la inducción al emprendimiento de quienes hasta ese entonces no tenían motivación al desplazamiento, por lo que el tesista considera oportuno mencionarlo.
} 
Otros inductores de la iniciación a la actividad empresarial, se relacionan con la experiencia laboral, por lo que el hecho de dominar algún rubro del negocio, inclinaría en algún momento a la toma de acción independiente aprovechando que se ha superado la curva de aprendizaje, reduciendo los riesgos y generando autoconfianza.

En la misma medida, el nivel educativo y el desarrollo de capacidades emprendedoras, sumado a la experiencia concreta en empresas, movilizan al individuo hacia la actividad independiente. Así lo han demostrado diversos estudios, que indican que en la etapa de estudiante, es cuando más ideas se pueden generar, por lo que la educación (formal y extracurricular), pasa a ser un activo intangible de incalculable valor, por los efectos que ella representa y significa. Tal situación es descripta de manera exhaustiva por Tomás Bulat (Bulat, 2015) en su libro "La economía de tu vida" (libro destinado a quienes quieren conocer acerca de las finanzas personales desde una óptica no profesional).

La percepción de los ingresos relativos, suelen explicar el pasaje del empleo hacia el autoempleo, en la medida en que quienes perciben bajos niveles salariales, se pueden ver empujados hacia una actividad independiente más rentable o escalable, al representar un costo de oportunidad ${ }^{8}$ relativamente bajo.

\subsection{Fomento del emprendedorismo}

\subsubsection{Rol estatal y acciones del estado}

El fomento del emprendedorismo, del empresarismo o del espíritu de creación de empresas, son las distintas maneras de nombrar la cultura del emprendimiento empresarial. Esto es un fenómeno que viene imponiéndose en

\footnotetext{
${ }^{8}$ El costo de oportunidad, es un concepto que proviene de la economía, y se lo define como "aquello a lo que renunciamos cuando tomamos una decisión económica", concepto incorporado por el economista Friedrich von Wieser en su Theorie der gesellschaftlichen Wirtschaft (Teoría de la economía social) publicada en el año 1914.
} 
el contexto mundial desde la década de 1990, pero que proviene de la época de entreguerras en el siglo XX como estrategia diseñada por los gobiernos europeos y el norteamericano, para hacerle frente al desempleo que se extendía por aquel entonces.

Un relevamiento exploratorio propio realizado por medio de las páginas web de las universidades más prestigiosas de Latinoamérica arrojó que, hoy, es común encontrar en algunas universidades de América Latina, por ejemplo, programas académicos apoyados por los diversos estados, que buscan fomentar la cultura del emprendimiento en los jóvenes estudiantes y en el conjunto de la sociedad o programas del gobierno, ya sea local o nacional, que apoyan iniciativas de creación de empresas y el autoempleo.

En Argentina específicamente, el Ministerio de Producción ${ }^{9}$ fomenta los "clubes de emprendedores", y en el reglamento que norma las condiciones para su reconocimiento, se determina que "La estrategia de trabajo está orientada a consolidar una mesa de trabajo local que debe estar conformada por el gobierno municipal o provincial y, al menos, dos organizaciones (universidades, organizaciones sin fines de lucro, empresas) que deben aportar el espacio físico, financiar un responsable que gerencie el lugar y con quienes se trabajará en el desarrollo estratégico del perfil y contenido del espacio"

Este fenómeno emprendedor, que tiene una explicación simple, resulta aparentemente paradójico, pues nace en un contexto de fuerte intervención estatal y nuevamente reaparece en un momento donde prima la libre competencia. Tanto en aquel momento como en la actualidad, el fomento de la cultura del emprendimiento ha sido una de las estrategias de los gobiernos para hacer frente a problemas políticos y sociales que genera el progreso del mercado.

\footnotetext{
${ }^{9}$ http://www.produccion.gob.ar/tag/emprendedores/ 
A principios del siglo $\mathrm{XX}$, los gobiernos promovieron el autoempleo como una forma política, económica y social de mantener ocupados en actividades provechosas para la sociedad a aquellos que no eran partícipes, por una u otra razón, de la maquinaria de guerra. Hoy, de nuevo, los gobiernos fomentan la cultura del emprendimiento como un mecanismo para crear empleo y competitividad, a la vez que busca aumentar los ingresos de los ciudadanos para mejorar el bienestar social y la gobernabilidad.

Casos emblemáticos como el ganador del premio nobel de la Paz, Muhammad Yunus en el año 2006 y el Banco Grameen fueron condecorados "por sus esfuerzos para incentivar el desarrollo social y económico desde abajo", en alusión al otorgamiento de microcréditos para el fomento del emprendedorismo en pequeña escala en las regiones pobres de Bangladesh, hoy tomado como modelo a nivel mundial. ${ }^{10}$ (Barilaro, 2016; Sanchez Tovar, García fernandez \& Mendoza Flores, 2015).

En Argentina, luego de las crisis del año 2001, los ministerios de economía nacional y provincial, a través de sus distintas secretarías, fomentaron órganos y organismos de pequeños y medianos emprendimientos, como ser la Secretaría de la Pequeña y Mediana Empresa (SePYME) y equivalentes a nivel provincial y/o local. En ellos, no solamente se promueve la formación emprendedora, sino que se canalizan créditos, aportes no reembolsables y se generan redes (clústers) regionales del fomento e integración regional.

Siguiendo estas tendencias, tanto en Argentina como en Colombia, Chile y México, se encuentra en reglamentación la Ley de emprendedores, que entre otras cosas propone simplificar el proceso de creación de empresas, fomento de nuevas figuras societarias, flexibilidad en la contratación y financiamiento

\footnotetext{
10 Según el diario la Nación del 2/3/2011, "El banco central de Bangladesh despojó a Yunus de sus funciones de director general del Grameen Bank con efecto inmediato". Dicha situación, se cree que no invalida la repercusión de su obra en los efectos del otorgamiento de microcréditos a emprendedores.
} 
colectivo del capital como forma de abrir accionariamente la participación de terceros. $^{11}$

Por citar ejemplos de otros países, en España rige la Ley 14/2013, de apoyo al emprendimiento, donde se señala que es necesario mejorar la eficacia de las políticas de apoyo institucional ofreciendo servicios de asistencia, información y asesoramiento colaborando con el sector privado incluso mediante el fomento mediante la financiación.

\subsubsection{Acciones de la universidad}

Sin lugar a dudas, la educación es la vía adecuada para la transmisión de nuevos conocimientos, sobre todo en países donde la cultura del emprendimiento no es una tradición. Aprender a ser creativo, innovador, líderes, realistas, orientados al objetivo, pareciera no ser posible, por ser más que todo rasgos vinculados a la personalidad. No obstante ello, sí es posible fomentar globalmente la mentalidad emprendedora promoviendo en aquellas personas la predisposición a emprender, sobre todo en quienes son emprendedores "latentes" y aún no lo saben (Fernandez Salinero \& de la Riva, 2014).

De acuerdo con el Global Entrepreneurship Monitor (G.E.M.), la educación emprendedora se define como "la disciplina que engloba los conocimientos y habilidades sobre el emprendimiento en general, sea reconocido como parte de los programas educativos, correspondiente a las enseñanzas en todos sus niveles" (Gomez Vallejo \& Satizabal Parra, 2011). En este aspecto, la participación de los profesionales como agentes de cambio en lo que es creación de nuevas empresas es de destacada importancia por la calidad de los conocimientos técnicos que aportan los mismos, y es desde la universidad donde se puede gestar sinérgicamente la combinación entre saber y hacer (teoría y práctica), en cuyo accionar se podrá gestar la actitud o cultura emprendedora.

11 Esta Ley (27.349) fue promulgada durante la elaboración de la tesis y se encuentra pendiente de reglamentación en algunos aspectos. 
Los programas de emprendimiento, en general, lo hacen equivalente con la creación de nuevas empresas y la creación de pequeños negocios, pero a decir de Kirby el énfasis en temas de negocios, no garantiza la formación de emprendedores (Kirby, 2004).

Así como se mencionan las competencias del emprendedor, también se deben mencionar las competencias básicas con las que debe contar el docente formador en emprendimiento. Dichas características y capacidades, orientadas a la formación, tiene que ver con asumir el rol de facilitador, enfoque sistémico y sustentable, planificación del proceso de aprendizaje basado en problemas, capacidad de desarrollar el trabajo en equipo, promotor y comunicador (Pertuz Peralta, Rojas Caicedo, Navarro Rodriguez, \& Quintero, 2015).

\subsection{El contador y el emprendedorismo}

\subsubsection{Formación de base y aptitudes}

Según el diccionario de la lengua española (RAE), la incumbencia es la "obligación y cargo de hacer algo", y en la actualidad, no emana otras acepciones. Sin embargo, las leyes de ejercicio profesional (Ley 10.620 Cap.2) en el caso de contadores matriculados en la Provincia de buenos Aires, hacen mención a las incumbencias, haciendo referencia a la obtención de requisito de contador público, para determinadas funciones, estudios y desempeños exclusivos de la profesión.

Desde este aspecto, podría decirse que las incumbencias, se acercan más a lo que se está permitido en términos del ejercicio profesional para una determinada profesión, y que lo separa de otras profesiones, hasta el punto de señalar como ejercicio ilegal de la profesión al desempeño de dichas tareas (incumbencias) (García \& Gomez Scavino, 2013).

De modo más preciso, la Ley de Educación Superior (Ley 24.521, Art. 42), y con un carácter más amplio, sin mencionar las incumbencias, hace explícita referencia a "Los conocimientos y capacidades que tales títulos certifican". Es 
decir, que alude al concepto contemporáneo compatible con el nuevo paradigma económico y social denominado competencia profesional.

Es así, que además de la formación propuesta por las universidades, las competencias valoradas por la sociedad, se vinculan más a la inteligencia emocional, la gestión del cambio, el comportamiento ético, iniciativa, emprendimiento, creatividad e innovación, entre otras (Gomez Vallejo \& Satizabal Parra, 2011). Se podría deducir entonces, que las competencias adquiridas y desarrolladas, tanto en la formación de grado como posteriormente, tienden a avalar los conocimientos adquiridos a los cuales la Ley hace mención.

La vocación emprendedora entonces, pasaría a ser un elemento de tipo subyacente en la formación, lo cual no lo hace menos importante. Todo lo contrario; se incorpora a las asignaturas de manera permanente por parte del docente, mediante el desarrollo de los contenidos, las ejercitaciones y la evaluación.

En cuanto a la formación de los formadores (docentes universitarios) de la carrera de contador, los mismos requerirán características y competencias nuevas que avalen ese elemento diferenciador. Dichas competencias (entre otras) se centran en la autonomía y autodirección del alumno, la promoción de proyectos basados en sus propias habilidades, y el efecto positivo del fracaso.

El análisis de los programas de estudio de la carrera de contador público de la facultad de ciencias económicas (Plan 6, que data del año 1992), no evidencia el desarrollo de esas habilidades emprendedoras que coadyuvan a la construcción del perfil buscado por el mercado laboral, orientado a la innovación, la creatividad y el emprendedorismo. A modo ejemplificativo, las guías de trabajos prácticos, en general, comienzan sus enunciados con frases tales como "Usted es un asesor...", "Una empresa requiere...", “Un cliente le solicita a Ud....", y en contadas ocasiones alude a frases del estilo. "Ud. va a invertir...." "Su empresa desea vender..." o "deberá decidir si va a....". Estas 
menciones, hacen clara referencia a que la orientación de dichos trabajos prácticos, se vinculan a un rol de asesor/empleado, por sobre la aplicación de los conocimientos en un rol de empresario/emprendedor.

En la actualidad, las empresas privadas constituyen el sector que más demanda los servicios de los Contadores Públicos, por lo que se observa interés de parte de los sectores relacionados con la formación profesional, por conocer la opinión de ese sector en cuanto a las competencias que el profesional tiene que demostrar en las actuales circunstancias del mercado laboral. (García \& Gomez Scavino, 2013) Tal vez sea esa una de las razones del enfoque al mercado laboral de las propuestas y ofertas educativas de las instituciones educativas de grado.

Un debate que se genera en el ámbito académico, se centra en la metodología de la enseñanza de las asignaturas del marco específico, sobre el fomento del pensamiento divergente, orientado a la creatividad (uno de los factores impulsores del espíritu emprendedor), y el pensamiento convergente que prevalece en la actualidad y en las estrategias de enseñanza del nivel superior. El pensamiento divergente, a partir de una idea o problema, "permite llegar a diferentes resultados, siendo flexible en la variedad de respuestas, mientras que el pensamiento convergente, ocurre cuando solamente se admite una solución lineal el problema" (Kastika, Introducción a la creatividad. , 2004).

Una alternativa para resolver esta barrera, es la aplicación de la metodología de casos, en el cual se valoran las actuaciones y fundamento de la soluciones y del aprendizaje basado en problemas (llamado APB), mediante el cual se cataliza el conocimiento por sobre la mera transmisión, en el cual el docente es un guía-gestor, y el alumno es un responsable por aprender a aprender (Litwin, 2006). 
La carrera de contador público, no exige para el ejercicio profesional una especialización o posgrado para desarrollarse profesionalmente. Toda ostentación de una especialización no avalada por una titulación, es causal de sanciones éticas (código de ética unificado de la FACPCE).

Las exigencias del mercado laboral, y del nuevo perfil profesional, hacen que mínimamente luego de la obtención del título de grado, se analicen las alternativas de formación de posgrado, tanto sea de especializaciones en distintas materias (menor carga horaria, de aplicación inmediata), como la realización de maestrías (requiere mayor carga horaria, de mayor espectro y de abordaje interdisciplinario).

Las distintas temáticas a las que se aluden en la formación de posgrado, además de contar con una mayor predisposición por aprender, por las condiciones previas de quienes asisten a dichos cursos, generan un espacio más abierto a la innovación y la creatividad. En algunos casos, podrá ser el punto de partida para generar ese espíritu o vocación emprendedora, la consolidación de la predisposición a emprender, o ratificar en cada uno de los asistentes a dichos posgrados, la negación de dicha vocación.

En el ámbito de la profesión del contador (como profesional matriculado), la FACPCE mediante el Sistema Federal de Actualización Profesional (SFAP), ofrece el conjunto de actividades académicas de actualización profesional en Ciencias Económicas, respaldado por los Consejos Profesionales y la FACPCE que, mediante el otorgamiento de créditos, reconoce el esfuerzo de los matriculados que se capacitan dentro y fuera del país. En la actualidad, esta formación es de carácter voluntario, lo cual no implique que la incorporación de la profesión dentro de los títulos que requieran validación periódica, no torne en compulsiva la actualización permanente en el futuro. 
Siguiendo la línea de la formación de bases y aptitudes, es importante traer a colación el concepto de "modelos mentales". Peter Senge (1995) en su libro la quinta disciplina, hace mención a los modelos mentales, diciendo que ellos “...determinan nuestro modo de percibir el mundo, nuestro modo de actuar y nuestro modo de sentir. Pueden ser generalizaciones, teorías, opiniones, paradigmas, en general son inconsciente por lo cual no se revisan." (Senge, 2011). Es evidente que el hecho de como un individuo percibe el mundo abre la posibilidad de subestimar o sobreestimar en el mundo de los negocios aquello que podrán ser oportunidades. El modelo mental no solo es construido por el contador durante su formación, sino por lo que el entorno de trabajo, colegas y valoración social conforman en él.

Socialmente, el contador en la actualidad representa una figura (siempre en términos generales) de una mentalidad tendiente a ser racional, más que intuitivo, un liquidador de impuestos, analista financiero o en todo caso un elaborador de estados contables (estados financieros o balances). Ese modelo mental puede incluir además ciertos paradigmas que se van creando paradigmas buenos, o paradigmas malos. Joel Barker (1995) menciona que un paradigma es "un conjunto de reglas y disposiciones implícitas o explícitas, que permiten establecer límites de una situación y cómo comportarse para tener éxito dentro de esos límites". Es así, como el contador va construyendo límites que lo llevan a priorizar su rol de asesor más que de actor en los negocios, a minimizar o relativizar el riesgo por sobre la experiencia de haber arriesgado su capital y prestigio ya optimizar recursos por sobre el efecto positivo de gastar el dinero sin esperar un retorno en términos financieros sobre la inversión.

La visión del emprendedor, en este sentido, es tal vez un poco más diferente. Donde el contador ve caos, confusión y peligros, el emprendedor (en su proceso de creación) ve claras oportunidades para acumular y controlar recursos e incrementarlos, con un sesgo de propensión al riesgo. 
En síntesis, dentro de los modelos mentales planteados por Serra (2000), el contador se encuentra por lo general en el modelo de tipo financiero, orientado a la producción, por sobre los modelos más orientados al marketing y al desarrollo sistémico y circular. No obstante ello, parece no encuadrar, al menos en este análisis, en el modelo orientado al producto o pre-Taylor (Serra, 2000). Es así, como en realidad la "mentalidad de contador" se va conformando en parte por la predisposición interna a la relación costo/beneficio, lo cual es ratificado por la formación que impone la creación de valor, las mediciones permanentes (y la orientación a los objetivos) y la minimización de riesgos o su diversificación.

Este modelo, gracias a las nuevas corrientes vinculadas a la economía social, la responsabilidad social empresaria, a la tolerancia al fracaso como forma de aprendizaje y la resiliencia, hacen que pueda crearse un nuevo paradigma acerca del nuevo rol del contador en la sociedad.

Es de esperar que con el transcurso del tiempo y el avance de los programas académicos, el contador público se resignifique no solamente en su denominación profesional, sino en su esencia hacia un profesional con aptitudes de hombre de negocios, sumado a una actitud favorable a la asunción del riesgo empresario y tolerancia al fracaso como forma de crecimiento no solamente personal, sino profesional.

\subsubsection{Competencias emprendedoras}

En los últimos años el concepto de competencias ha tenido mayor auge en los campos educativo y organizacional de la Psicología a nivel mundial, siendo numerosos los investigadores que se han acercado a su estudio. Las competencias, ya sean laborales, profesionales, o educativas, se han definido en la literatura sobre el tema de diversas formas, existiendo tantas definiciones del término, como autores y conceptos sobre su origen y naturaleza. Esta multiplicidad de definiciones evidencia que aún se carece de una acepción 
clara y compartida de este concepto y que aún falta mucho por explorar y conocer sobre esta temática.

Se puede concluir que las competencias son características permanentes de las personas, se ponen de manifiesto cuando se ejecuta una tarea, se relacionan con la ejecución exitosa en una actividad, tienen una relación causal con el rendimiento laboral y se pueden generalizar a más de una actividad. Una competencia es la capacidad de seguir en el área determinada; supone una situación de comparación directa y situada en un momento determinado. A partir del siglo XV, competer comienza a adquirir el significado de pertenecer a, incumbir, corresponder a. De esta manera se constituye el sustantivo competencia y el adjetivo competente, cuyo significado comienza a ser el de apto o adecuado.

Una forma de definir a la mentalidad emprendedora, es a través de sus cualidades más significativas, las cuales pueden resumirse, en: liderazgo, creatividad, pasión, confianza, determinación, organización, mentalidad abierta, realismo, negociación y actitud positiva frente al futuro (Fernandez Salinero \& de la Riva, 2014).

Los autores mayoritariamente coinciden en que se puede aprender a ser emprendedor, ya que más de una característica intrínseca del emprendedor se trata de una conducta que se aprende. En un trabajo presentado por docentes en administración de Colombia (Correa Correa, Delgado Hurtado, \& Conde Cardona, 2005), se brindan dichas justificaciones, mencionando diversos autores.

Gibb (2002) afirma que la educación en emprendimiento demanda de la integración del conocimiento de varias disciplinas, mayores oportunidades para desarrollar espacios de aprendizaje experiencial, y la necesidad de ampliar de manera apropiada comportamientos, actitudes y habilidades emprendedoras. Plantea como competencias fundamentales para el emprendimiento, la competencia para comunicarse de manera efectiva; la capacidad para tolerar y 
sobrellevar la ambigüedad e incertidumbre y tomar decisiones en estas condiciones.

Pero no solo Gibb dedica parte de su obra a identificar competencias emprendedoras. Son varios los autores que se abocan a esta tarea. Podemos encontrar a entre otros a Kirby (2004) quien manifiesta que la principal competencia que tiene un emprendedor es, entre otras, la aptitud para asumir riesgos, es decir, la capacidad para tolerar la ambigüedad e incertidumbre. Sarasvathy (2011) menciona que el ejercicio del emprendimiento requiere competencias como la resolución de problemas, trabajo en equipo, manejo de la incertidumbre y capacidad para conformar redes sociales. Timmons (1999) señala como competencias críticas del emprendedor, la construcción de relaciones cercanas; saber manejar las paradojas y contradicciones, manejo de la ambigüedad; capacidad para la creación de grupos de trabajo; la perseverancia; y la iniciativa dado su insatisfacción constante con el statu quo. Gómez y Satizábal (2011) identifican como competencias emprendedoras, la conformación de redes; la resolución de problemas; asumir riesgos; orientación al logro y a las oportunidades; trabajo en equipo; autonomía; creatividad e iniciativa. 
Tabla № 1: Competencias por autores contemporáneos

\begin{tabular}{|l|c|c|c|c|c|}
\hline \multicolumn{1}{|c|}{ Competencias/Autores } & Gibb & Sarasvathy & Kirby & $\begin{array}{c}\text { Gómez y } \\
\text { Satizábal }\end{array}$ & Timmons \\
\hline $\begin{array}{l}\text { Conocimiento } \\
\text { interdisciplinario }\end{array}$ & $\square$ & & & & \\
\hline $\begin{array}{l}\text { Habilidades y actitudes } \\
\text { emprendedoras }\end{array}$ & $\square$ & & & & \\
\hline Resolución de problemas & & $\square$ & & $\square$ & \\
\hline Trabajo en equipo & & $\square$ & & $\square$ & \\
\hline Administración de redes & & $\square$ & & $\square$ & $\square$ \\
\hline $\begin{array}{l}\text { Manejo de la } \\
\text { incertidumbre }\end{array}$ & & $\square$ & $\square$ & & $\square$ \\
\hline Perseverancia & & & & & $\square$ \\
\hline Orientación al logro & & & & $\square$ & \\
\hline Creatividad e iniciativa & & & & $\square$ & \\
\hline
\end{tabular}

Fuente: Elaboración propia

Lo que queda claro es que el desarrollo de competencias para los emprendedores de la Universidad trasciende más allá de la formación en contenidos orientados hacia lo funcional. Es fundamental considerar acciones de desarrollo encaminadas al desarrollo de competencias conductuales para que el emprendedor pueda tener éxito. En este orden de ideas, Kirby (2004), plantea que los programas de emprendimiento en las instituciones educativas, por lo general, no educan para el emprendimiento, sino que orientan acerca del mismo y de la empresa, y no se centran en las habilidades, atributos y competencias de un emprendedor exitoso. Al contrario, focalizan la enseñanza en la creación de nuevas empresas y la administración de negocios, aspectos que no son suficientes para garantizar la formación de estudiantes emprendedores, por lo que debe fortalecerse también el desarrollo de los atributos, manera de pensar y comportarse de los emprendedores. 
Los resultados de dicha investigación, en la cual se propone "identificar y conceptualizar las competencias para el emprendimiento a desarrollar en los estudiantes de Administración de Empresas de una universidad pública con el fin de impulsar nuevos proyectos y la creación de empresas", concluyen que mediante la revisión de la literatura especializada en competencias emprendedoras, de las 20 competencias relevadas, las 5 más importantes son:

Tabla № 2: Competencias relevadas

\begin{tabular}{|l|l|r|}
\hline $\mathbf{N}^{\mathbf{0}}$ & Competencia emprendedora & Porcentaje \\
\hline 1 & Riesgos calculados & 70.3 \\
\hline 2 & Iniciativa/autonomía & 59.5 \\
\hline 3 & Innovación/creatividad & 56.8 \\
\hline 4 & Orientación a resultados & 45.9 \\
\hline 5 & Confianza en él mismo & 35.1 \\
\hline
\end{tabular}

Fuente: (Correa Correa, Delgado Hurtado, \& Conde Cardona, 2005, pág. 8)

Esta investigación sirvió de base para la preparación de las encuestas realizadas para conocer la vocación emprendedora (VE) del contador público y realizar análisis, comparaciones y obtención de resultados.

En este sentido, es poco lo que se ha avanzado en la educación en emprendimiento en las universidades de Argentina, y se carece de estudios que focalicen en las características de las empresas y del proceso emprendedor de los graduados, donde la investigación en este campo se encuentra en un estado embrionario, aunque con un creciente interés en los últimos años. Surge de lo anterior, la necesidad de estudiar el proceso emprendedor haciendo hincapié en un tipo especial de emprendedores, los graduados universitarios, e identificar las competencias emprendedoras a desarrollar para formar estudiantes emprendedores exitosos.

Con respecto a la incidencia de las facultades sobre la probabilidad de que un profesional adquiera características emprendedoras, se puede citar al trabajo de Liseras y Rearte (Liseras, Gennero de Rearte, \& Graña, 2003, pág. 17) 
donde se obtuvieron interesantes conclusiones como se mencionan a continuación:

1. La vocación emprendedora se incrementa en el caso de los hombres ocupados con valoración de la actividad empresarial, adverso al riesgo y con altos niveles de creatividad.

2. Si se incorpora la incidencia de la facultad, la vocación emprendedora aumenta en mayor medida en las universidades privadas, en poblaciones con alumnos de mayores ingresos, con mayores redes de contactos y con apoyo de entidades financieras.

3. La localización geográfica, incide en la vocación, en la medida en que los polos agroindustriales son más amigable al emprendedorismo, como ser el caso del interior de la Provincia de Buenos Aires o Rosario por citar ejemplos, mientras que en ciudades de tipo capitales como La Plata, la formación se orienta más al empleo público y privado, con orientación en Pymes mayoritariamente.

4. Ninguna de las facultades de ese estudio poseía al momento de la investigación programas (de grado) orgánicos orientados a la creación de empresas.

Como conclusión de dicho trabajo, los autores señalan que "estimular el surgimiento de capacidades emprendedoras en los futuros profesionales, quienes evalúen la creación de una empresa propia como opción de carrera, es un aspecto fundamental a la hora de pensar las posibilidades de reproducción de la base empresarial necesaria para un proceso de desarrollo económico" (Liseras, Gennero de Rearte, \& Graña, 2003)

A modo de ejemplo se puede citar e la propuesta de currículo de la Universidad Javeriana de Cali, en el cual se exponen y proponen las siguientes competencias emprendedoras: 
Tabla $\mathrm{N}^{\circ} 3$

\begin{tabular}{|l|l|l|}
\hline$N^{0}$ & \multicolumn{1}{|c|}{ Competencia } & \multicolumn{1}{c|}{ Resumen } \\
\hline 1 & $\begin{array}{l}\text { Conformación de } \\
\text { redes }\end{array}$ & $\begin{array}{l}\text { Promoción del contacto personal y ampliación del } \\
\text { entorno }\end{array}$ \\
\hline 2 & $\begin{array}{l}\text { Resolución de } \\
\text { problemas }\end{array}$ & $\begin{array}{l}\text { Habilidad para encontrar diferentes soluciones } \\
\text { situaciones }\end{array}$ \\
\hline 3 & Orientación al logro & $\begin{array}{l}\text { Poder identificar oportunidades y realizarlas (con } \\
\text { éxito) }\end{array}$ \\
\hline 4 & Asunción de riesgos & Conocimiento de que los hechos pueden salir mal \\
\hline 5 & Trabajo en equipo & $\begin{array}{l}\text { Se fomenta la sinergia interdisciplinaria y } \\
\text { liderazgo }\end{array}$ \\
\hline 6 & Creatividad & $\begin{array}{l}\text { Capacidad de asociar ideas y asociaciones } \\
\text { originales }\end{array}$ \\
\hline 7 & Autonomía & Independencia y capacidad de autogobierno \\
\hline 8 & Iniciativa & Salir de la insatisfacción del status quo \\
\hline
\end{tabular}

Fuente: Adaptación propia del cuadro de competencias emprendedoras de la Universidad Javeriana de Cali. (Gomez Vallejo \& Satizabal Parra, 2011)

Otras competencias no enunciadas en esta tabla, pero que surgen de autores como Gibb (1982), Kirby (2004), Sarasvathy (2011) y Timmons (2007), son: resiliencia, perseverancia, comunicación efectiva, pensamiento crítico y visión de oportunidades.

Desde el punto de vista de la didáctica, se puede reflexionar acerca de qué manera incorporar dichas competencias dentro del cúmulo de conocimientos a los alumnos universitarios, dado que lo que se procura en este tipo de educación es incorporar métodos del “¿cómo se hace?", más que el “¿qué se hace?". Por lo tanto, se deben definir las etapas en las cuales se deben incorporar dichas habilidades mediante una regulación de los aspectos cognitivos. 
Desde esta óptica, las estrategias de enseñanza y aprendizaje utilizadas en emprendimiento deben ser diseñadas con la intencionalidad clara obre los objetivos que se quieren lograr y el valor agregado de la institución educativa sobre el estudiante. Esto se puede lograr mediante la implementación de actividades y experiencias educativas enfocadas al desarrollo de competencias emprendedoras.

El estudio de casos, la resolución de problemas, el pensamiento crítico y reflexivo, se consideran que son los mecanismos adecuados para este tipo de enseñanza, donde se asume el error como parte del aprendizaje, la devolución como una crítica constructiva hacia el estudiante y una perspectiva de aprender emprendiendo. En estas estrategias pedagógicas la modelización y simulación son ejes fundamentales por sobre las clases magistrales. Esto se condice con las tendencias educativas vinculadas al constructivismo en educación ${ }^{12}$.

A partir de ello, es que los diseños de contenidos y propuestas pedagógicas, tienden a aprender sobre la solución de problemas concretos, lo que según Pozo y Pérez Echeverría (2009) proponen, al "evitar preguntas y tareas que permitan respuestas reproductivas y evitando que esté la respuesta correcta, literalmente incluida en los materiales..." (Pozo \& Perez Echevarría, 2009, pág. $62)$.

\footnotetext{
${ }^{12}$ El constructivismo, es una corriente educativa opuesta a la corriente tradicional denominada conductismo. Sus exponentes fueron Piaget y Vygotski y Ausubel, proponiendo a mediados del siglo XX como proceso modernista, el aprendizaje es resultado de un proceso de construcción y reconstrucción de significados. El Currículum se ve como proceso y resolución de problemas. La enseñanza se basa en situaciones problemáticas. El rol del docente es facilitador, orientador, intermediario en el proceso. El alumno es el protagonista y constructor de su propio aprendizaje.
} 


\section{Preguntas de la tesis}

En base a los objetivos planteados, tanto generales y particulares, se pueden plantear las siguientes preguntas:

1) ¿Cuentan los contadores públicos con mayor vocación emprendedora que el resto de las profesiones universitarias?

2) ¿Prevalecen las aptitudes de formación de grado y extracurricular, por sobre la actitud emprendedora en cuanto a la contribución de la vocación emprendedora?

3) ¿Es la formación emprendedora de la Facultad de Ciencias Económicas de la U.N.L.P. insuficiente, y hace necesario recibir formación adicional que permitan ejercer acciones emprendedoras?

4) La aversión al riesgo en el contador: ¿se encuentra por encima de otras profesiones liberales a analizar, e impide el fortalecimiento de una cultura emprendedora?

5) La edad y la experiencia, tomada como la cantidad de años de graduado de la facultad, ¿incrementan la vocación emprendedora del contador?

\section{El Sistema de Variables}

A priori, no se sabe si se podrá explicar el comportamiento de un profesional en cuanto al grado de vocación o preferencia por el desarrollo de nuevos negocios. Es decir, que el tipo de variables a analizar, serán las del tipo "variables intervinientes", por lo que no se pueden medir de manera precisa y/o cuantificarse como para medir una "propensión al emprendimiento". De todas maneras, se intentará explicar cuáles son las variables que incidirán en la predisposición a la actividad empresarial por parte de los contadores.

Se propone desarrollar un índice de vocación emprendedora del contador (VEC), determinado por un valor máximo de 100 puntos, que se compondrá de acuerdo a la tabla $n^{\circ} 4$. Para las opciones de sí o no, el valor "no" implica cero, y el valor "sí", el que asume entre paréntesis. 
Tabla No 4: Variables, puntajes e indicadores

\begin{tabular}{|l|c|l|l|}
\hline \multicolumn{1}{|c|}{ Variable } & $\begin{array}{c}\text { Denominación } \\
\text { y puntaje }\end{array}$ & \multicolumn{1}{|c|}{ Indicador } & \multicolumn{1}{|c|}{ Pregunta } \\
\hline $\begin{array}{l}\text { Propósito } \\
\text { emprendedor }\end{array}$ & $\begin{array}{c}\text { Intención } \\
(10)\end{array}$ & $\begin{array}{l}\text { Profesionales que } \\
\text { actualmente tienen un } \\
\text { proyecto concreto para } \\
\text { crear una empresa propia, } \\
\text { pero nunca lo han hecho }\end{array}$ & $\begin{array}{l}\text { ¿Tiene proyectado en algún } \\
\text { momento de su vida crear su } \\
\text { propia empresa? (solo o } \\
\text { asociado) }\end{array}$ \\
\hline $\begin{array}{l}\text { Conducta } \\
\text { emprendedora }\end{array}$ & $\begin{array}{c}\text { Conducta } \\
(10)\end{array}$ & $\begin{array}{l}\text { Profesionales que alguna } \\
\text { vez iniciaron una empresa } \\
\text { propia. }\end{array}$ & $\begin{array}{l}\text { ¿Participa o ha participado en } \\
\text { algún momento en la creación de } \\
\text { alguna empresa, no importa su } \\
\text { dimensión? }\end{array}$ \\
\hline $\begin{array}{l}\text { Creatividad e } \\
\text { innovación }\end{array}$ & $\begin{array}{c}\text { Creatividad } \\
(20)\end{array}$ & $\begin{array}{l}\text { Profesionales que se } \\
\text { consideran en algún } \\
\text { aspecto creativo o } \\
\text { innovador }\end{array}$ & $\begin{array}{l}\text { ¿Considera Ud. que es creativo o } \\
\text { innovador en algún aspecto de su } \\
\text { vida y/o profesión? }\end{array}$ \\
\hline $\begin{array}{l}\text { Aversión o } \\
\text { propensión al } \\
\text { riesgo }\end{array}$ & $\begin{array}{c}\text { Riesgo } \\
(20)\end{array}$ & $\begin{array}{l}\text { Según el profesional se } \\
\text { considere su postura frente } \\
\text { al riesgo }\end{array}$ & $\begin{array}{l}\text { ¿Se considera Ud. cercano a } \\
\text { asumir riesgos, el estrictamente } \\
\text { necesario, o le escapa al riesgo } \\
\text { en los negocios? }\end{array}$ \\
\hline $\begin{array}{l}\text { Cultura } \\
\text { empresarial }\end{array}$ & $\begin{array}{c}\text { Negocios } \\
(10)\end{array}$ & $\begin{array}{l}\text { Según el profesional se } \\
\text { considere hombre/mujer de } \\
\text { negocios }\end{array}$ & $\begin{array}{l}\text { ¿Se considera un hombre/mujer } \\
\text { de negocios? }\end{array}$ \\
\hline $\begin{array}{l}\text { Formación de } \\
\text { grado }\end{array}$ & $\begin{array}{l}\text { Grado } \\
(20)\end{array}$ & $\begin{array}{l}\text { Según el profesional } \\
\text { considere que haya } \\
\text { recibido formación en } \\
\text { emprendimiento en la } \\
\text { Universidad }\end{array}$ & $\begin{array}{l}\text { ¿Considera Ud. que ha recibido } \\
\text { herramientas para el desarrollo } \\
\text { de emprendimientos en su } \\
\text { formación universitaria? }\end{array}$ \\
\hline $\begin{array}{l}\text { Formación } \\
\text { extracurricular }\end{array}$ & $\begin{array}{c}\text { Extracurricular } \\
(10)\end{array}$ & $\begin{array}{l}\text { Profesionales que han } \\
\text { tomado cursos } \\
\text { relacionados con la } \\
\text { actividad empresaria }\end{array}$ & $\begin{array}{l}\text { ¿Ha tomado cursos fuera del } \\
\text { ámbito académico vinculados a la } \\
\text { actividad empresarial? }\end{array}$ \\
\hline
\end{tabular}

Fuente: Elaboración propia

El índice quedaría expresado de la siguiente manera:

\section{VEC $=$ PE+CE+Cl+PR+CE+FG+FE}

Donde:

$\mathrm{VEC}=\operatorname{Max}=100$ pts.

PE: Propósito emprendedor. $\mathrm{Si}=10 ; \mathrm{No}=0$

CE: Conducta emprendedora. $\mathrm{Si}=10 ; \mathrm{No}=0$

$\mathrm{Cl}$ : Creatividad e innovación. $\mathrm{SI}=20 ; \mathrm{No}=0$

PE: Propensión al riesgo. Propenso $=20 ;$ Neutro $=10 ;$ Adverso $=0$

CE: Cultura empresarial. $\mathrm{Si}=10 ; \mathrm{No}=0$

FG: Formación de grado. $\mathrm{SI}=20 ; \mathrm{No}=0$

FE: Formación extracurricular. SI= 10; No=0 


\section{Metodología de la investigación}

\subsection{Tipo de investigación}

Se propone efectuar una investigación de tipo exploratoria/descriptiva no experimental, en la cual se miden y analizan variables con el fin de especificar las propiedades importantes del grupo de contadores. El énfasis está en el estudio independiente de cada característica, integrando en algunas las mediciones de dos o más características con el fin de determinar cómo es o cómo se manifiesta el fenómeno. Pero en ningún momento se pretende establecer la forma de relación entre estas características.

\subsection{Población y Muestra}

La investigación requirió de dos poblaciones diferentes.

La primera conformada por los contadores graduados en la U.N.L.P. Ante la imposibilidad de contar con un padrón sobre el cual realizar un muestreo aleatorio se recurrió a un muestreo por oportunidad. Se confeccionó una base de datos de elaboración propia consistente en contactos de ex alumnos desde el año 2002 a 2016, de contactos personales siendo colegas de la profesión, docentes colegas de la Facultad de Ciencias Económicas de la U.N.L.P, y contactos de la red social Linked In, con el solo requisito que se hayan graduado en el país, y verificando su condición de graduado en UNLP en el detalle de perfil de dicha red. La muestra constó de 216 profesionales contadores en total, donde recibieron 50 respuestas positivas en dicho lapso, con un $23 \%$ de tasa de respondientes.

Para el caso de la segunda población, confirmada por el resto de los profesionales no contadores de cualquier universidad de Argentina, se realizó el mismo procedimiento de muestreo. La muestra constó de 167 profesionales no contadores en total, donde recibieron 75 respuestas positivas en dicho lapso, con un $45 \%$ de tasa de respondientes. Dichos profesionales, fueron 
agrupados, dada la diversidad de profesiones, tal como se muestra en el siguiente cuadro:

Tabla 5: Muestra de profesionales no contadores

\begin{tabular}{|l|r|}
\hline \multicolumn{1}{|c|}{ Profesión } & Frecuencia \\
\hline Arquitectura e Ingeniería & 21 \\
\hline Educación & 7 \\
\hline Leyes & 5 \\
\hline Otras ciencias económicas & 16 \\
\hline Salud & 11 \\
\hline Sistemas & 9 \\
\hline Otras profesiones independientes & 6 \\
\hline Total & 75 \\
\hline
\end{tabular}

Fuente: Elaboración propia

\subsection{Técnicas de recolección de datos}

Los datos que se recolectaron, provienen de:

- Encuestas realizadas a contadores graduados de la U.N.L.P.

- Encuestas realizadas a otros profesionales universitarios.

La investigación se llevó a cabo mediante encuestas a profesionales graduados que desarrollan la actividad de contador, ya sea mediante el ejercicio independiente y/o en relación de dependencia. Se elaboró una encuesta destinada a profesionales no necesariamente matriculados, para no sesgar la investigación.

A su vez se reformaron los contenidos del marco teórico y su vinculación con la realidad de la población aludida por medio de entrevistas personales a docentes, alumnos de la carrera de contador público y docentes de dicha carrera. 
Las encuestas fueron canalizadas por email mediante software libre que permite la obtención de los datos de manera lineal, mientras que el análisis fue llevado a cabo, tanto para su presentación como en la vinculación de las variables, mediante planilla de cálculo.

La ventaja de este método, radica en la velocidad de respuesta, en la medida que entre el 08/12/2016 y 15/12/2016 se enviaron 216 solicitudes y el 24/12/2016 se recibieron 50 respuestas positivas, sin insistencia o recordatorio, mientras que las consultas a otros profesionales se enviaron 167 solicitudes desde el 12/12/2016 y al 24/12/2016 se recibieron 75 respuestas positivas, con un recordatorio el día 20/12/2016. Cabe destacar, que de la base de datos de contadores, menos del $30 \%$ conocían al tesista (colegas y exalumnos), mientras que de los restantes profesionales, el 90\% conocían al tesista, lo que podría explicar la alta tasa de respuesta, sobre todo por la reiteración de la solicitud.

\subsection{Técnicas de análisis}

Se realiza un análisis lógico de los puntos de las encuestas que se puedan compilar para luego clasificar y analizar. También se realiza un análisis comparativo entre las distintas profesiones universitarias.

Dado que se supone que la correlación de las variables de la VEC es positiva (las variables son directamente proporcionales con la VEC), es preciso destacar, que las mismas se pueden subdividir en variables actitudinales (el propósito y actitud a emprender), instrumentales (formación) y psicológicas (culturales/propensiones al riesgo)

De este modo, serán agrupadas para determinar si las características diferenciadoras en más o en menos, se deben a estos tipos de subgrupos.

De la base de datos delas personas relevadas, se conserva una copia de las mismas y los resultados de manera individual para una auditoría de la 
compilación, como así también de las solicitudes de encuestas de no respondientes.

Para poder arribar a las conclusiones, se ha determinado una sumatoria aritmética del puntaje de la tabla 2 para construir el grado de vocación emprendedora del contador (VEC). Un valor menor a 40, conlleva un bajo grado de vocación emprendedora, un grado superior a 70 se lo considera una alta vocación emprendedora, mientras que valores intermedios son asociados a un valor intermedio o moderado en dicha cultura.

Gráfico Nº 1 Escala de medición de la V.E.

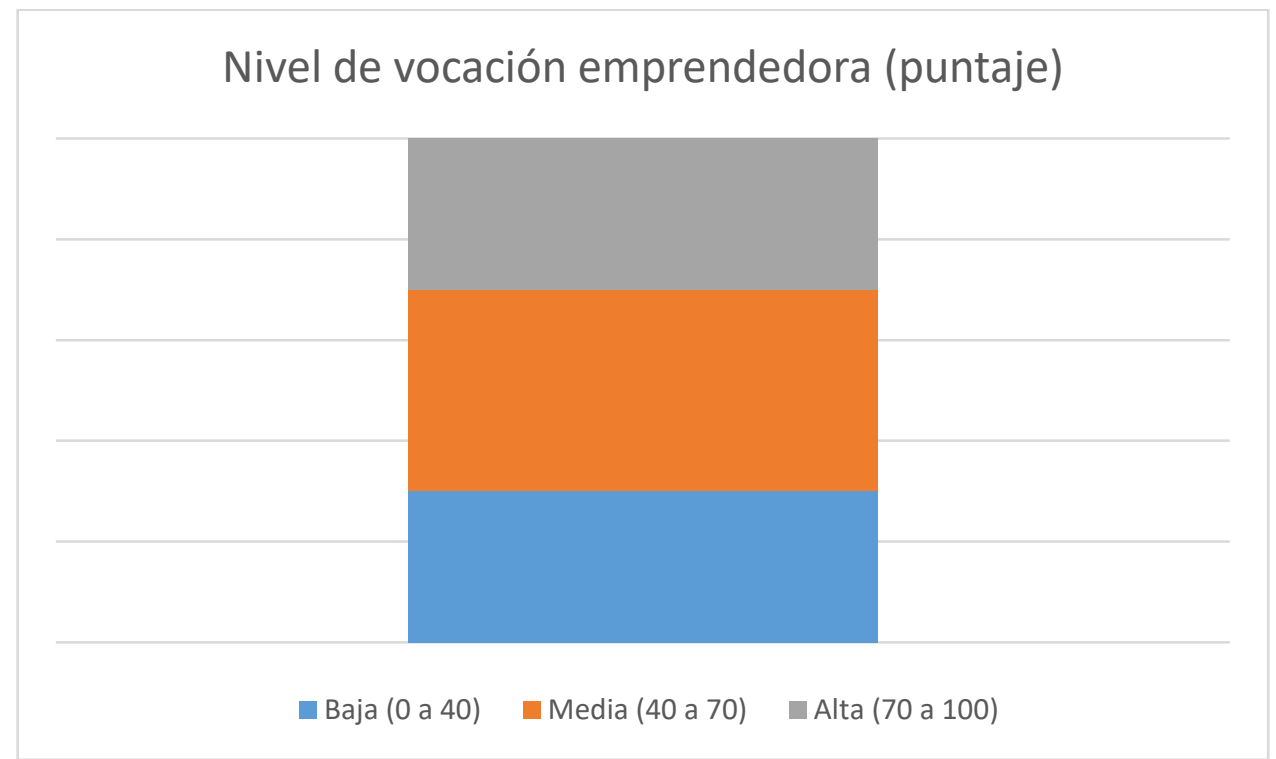

Fuente: Elaboración propia.

Para arribar a conclusiones acerca de las características del grupo de contadores, se han realizado las mismas encuestas a un grupo de 75 profesionales no contadores, de los cuales 16 son profesionales de las ciencias económicas, tal como surge de la tabla 4 (licenciados en administración y en economía), por lo que al ser escaso el número de ese tipo de profesionales, no se realizó análisis comparativo con dichas profesiones. 


\section{Resultados obtenidos}

\subsection{Análisis primario}

A continuación se presenta la estimación de la tasa de contadores con vocación emprendedora y se comentan las características actitudinales, instrumentales y psicológicas, analizadas dentro del grupo de contadores, tal como se detalla en el siguiente cuadro.

Tabla 6: Agrupamiento de variables y géneros

\begin{tabular}{|c|c|}
\hline Variable & Género \\
\cline { 1 - 1 } $\begin{array}{c}\text { Intención } \\
\text { emprendedora }\end{array}$ & \\
\cline { 1 - 1 } $\begin{array}{c}\text { Conducta } \\
\text { emprendedora }\end{array}$ & Actitudinales \\
\cline { 1 - 1 } $\begin{array}{c}\text { Hombre o mujer de } \\
\text { negocios }\end{array}$ & \\
\cline { 1 - 1 } $\begin{array}{c}\text { Herramientas para el } \\
\text { emprendimiento }\end{array}$ & \multirow{2}{*}{ Instrumentales } \\
\cline { 1 - 1 } $\begin{array}{c}\text { Toma de cursos } \\
\text { extracurriculares }\end{array}$ & \\
\cline { 1 - 2 } $\begin{array}{c}\text { Creatividad e } \\
\text { innovación }\end{array}$ & \multirow{2}{*}{ Psicológicas } \\
\cline { 1 - 2 } $\begin{array}{c}\text { Posición frente al } \\
\text { riesgo Psicológica }\end{array}$ & \\
\hline
\end{tabular}

Fuente: Elaboración Propia

Como principio general, se observó que el nivel promedio de vocación emprendedora llegó al valor de 54,5 de promedio, con un desvío (dispersión) de 22,60.

a) Proporción de contadores con vocación emprendedora

De los 50 contadores analizados, se concluye que el $24 \%$ de ellos poseen un nivel de VEC bajo (inferior a 40 ), mientras que el $54 \%$ se encuentran en el tercio medio (entre 40 y 70 ), y el $22 \%$ restante presentan una VEC alta (mayor a 70$)$. 
Gráfico № 2: Proporción de contadores con V.E.

\section{Contadores con VE (en tercios)}

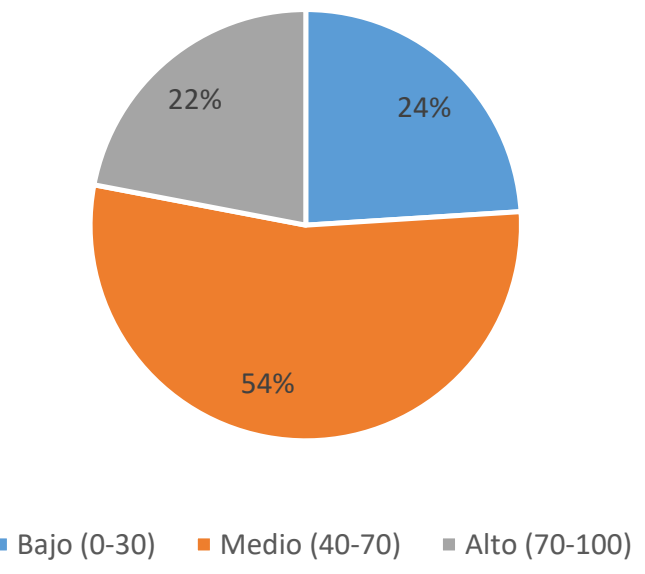

Fuente: Elaboración Propia

Si se quisiera agrupar entre los que tienen una VEC baja o alta (dividiendo la muestra en mitades), se encuentra que la mitad poco emprendedora representa el $34 \%$, mientras que la mitad emprendedora, representa el $66 \%$.

Gráfico Nº 3: Proporción de contadores con V.E.

\section{Contadores con VE (en medios)}

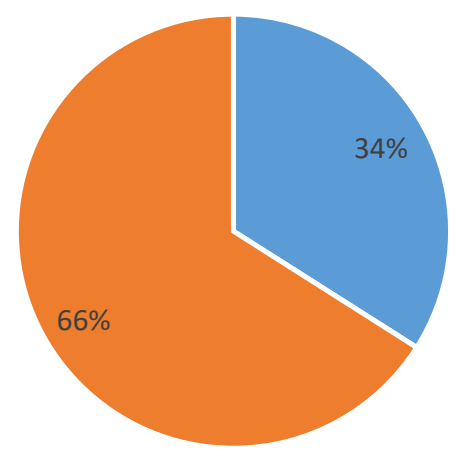

- Bajo (0-40) - Alto (50-100)

Fuente: Elaboración propia 
b) Características personales de los emprendedores

Las características actitudinales que definen a los contadores en base a la intención y comportamiento emprendedor, se explican en la medida en que el $72 \%$ de los contadores tiene pensado establecer un nuevo emprendimiento en algún momento y el $52 \%$ ya lo ha materializado en alguna medida. El $68 \%$ de la muestra, se siente hombre de negocios.

Gráfico Nº 4: Medición de variables actitudinales

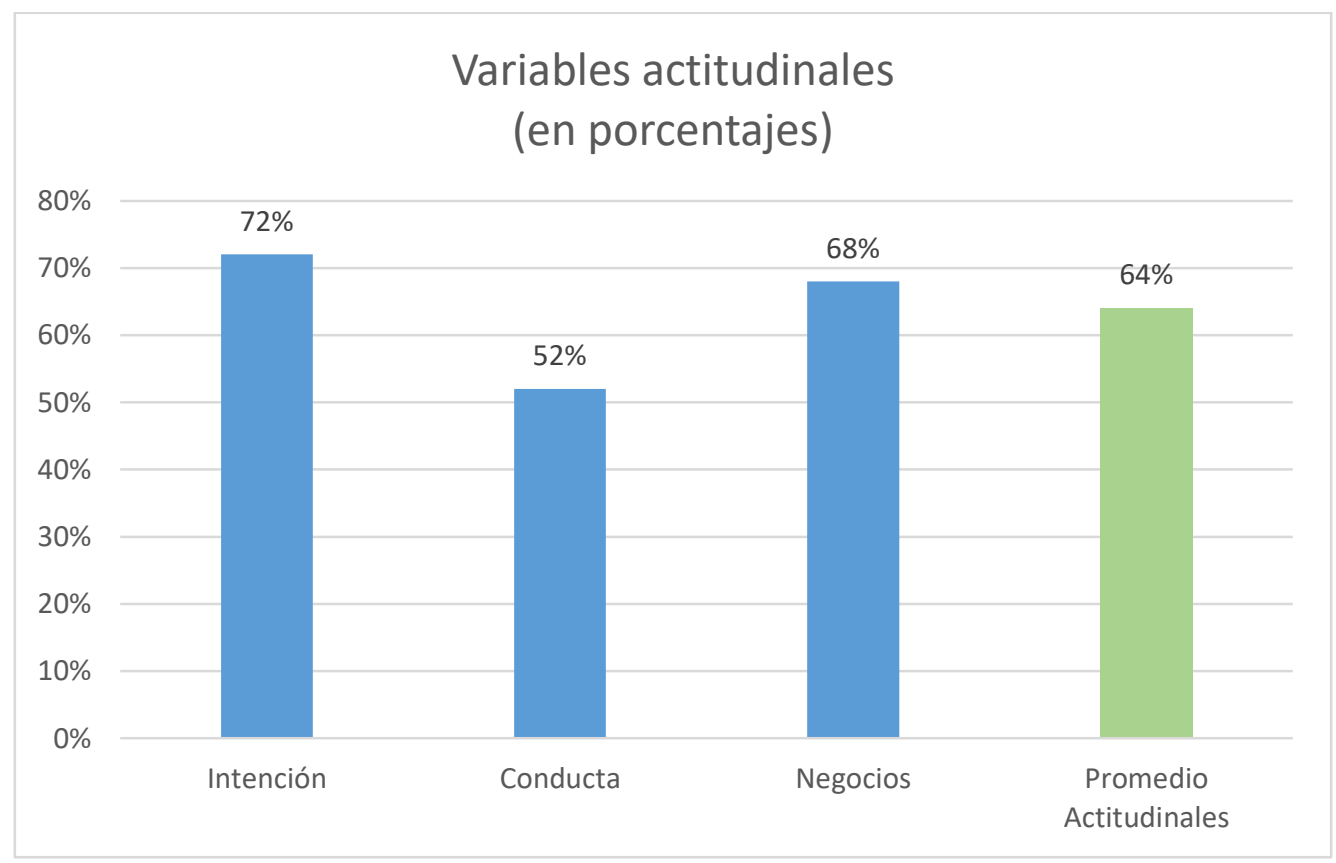

Fuente: Elaboración propia

c) Factores vinculados a la formación (elementos instrumentales)

En base a la formación de grado recibida, el $50 \%$ de los contadores, considera que la formación de grado le brinda pocas herramientas para el emprendimiento. De este total, $36 \%$ ha tomado cursos extracurriculares. 
Gráfico № 5: Variable instrumental

Herramientas para el emprendimiento

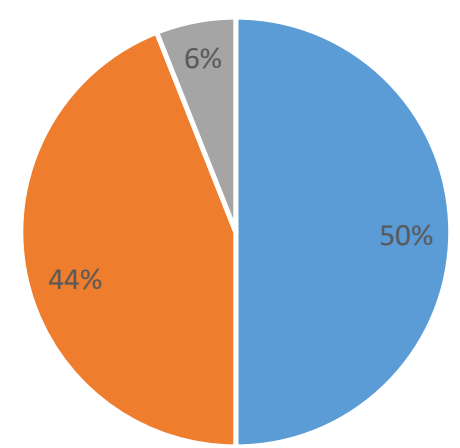

- Pocas $\square$ Suficientes $\square$ Muchas

Fuente: Elaboración propia

d) Factores psicológicos

La propensión al riesgo se manifiesta en el $10 \%$ de los casos. El $18 \%$ de los contadores se consideran adversos, y el resto (un $72 \%$ ) son neutros ante el riesgo en los negocios.

Gráfico N 6: Percepción del riesgo

\section{Propensión al riesgo}

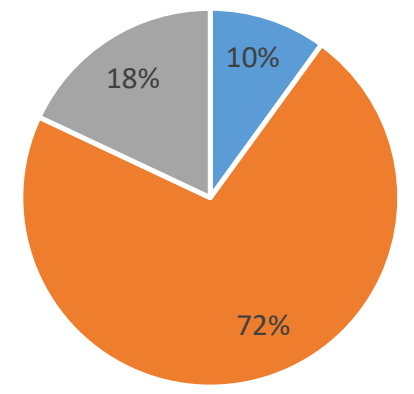

- Propensos

Fuente: Elaboración propia 
En cuanto a la creencia acerca de ser creativo o innovador, $2 / 3$ de ellos se consideran creativos o innovadores, siendo que es el mayor valor representativo de todas las variables que se resumen en el siguiente gráfico.

Gráfico № 7: Resumen de las principales variables

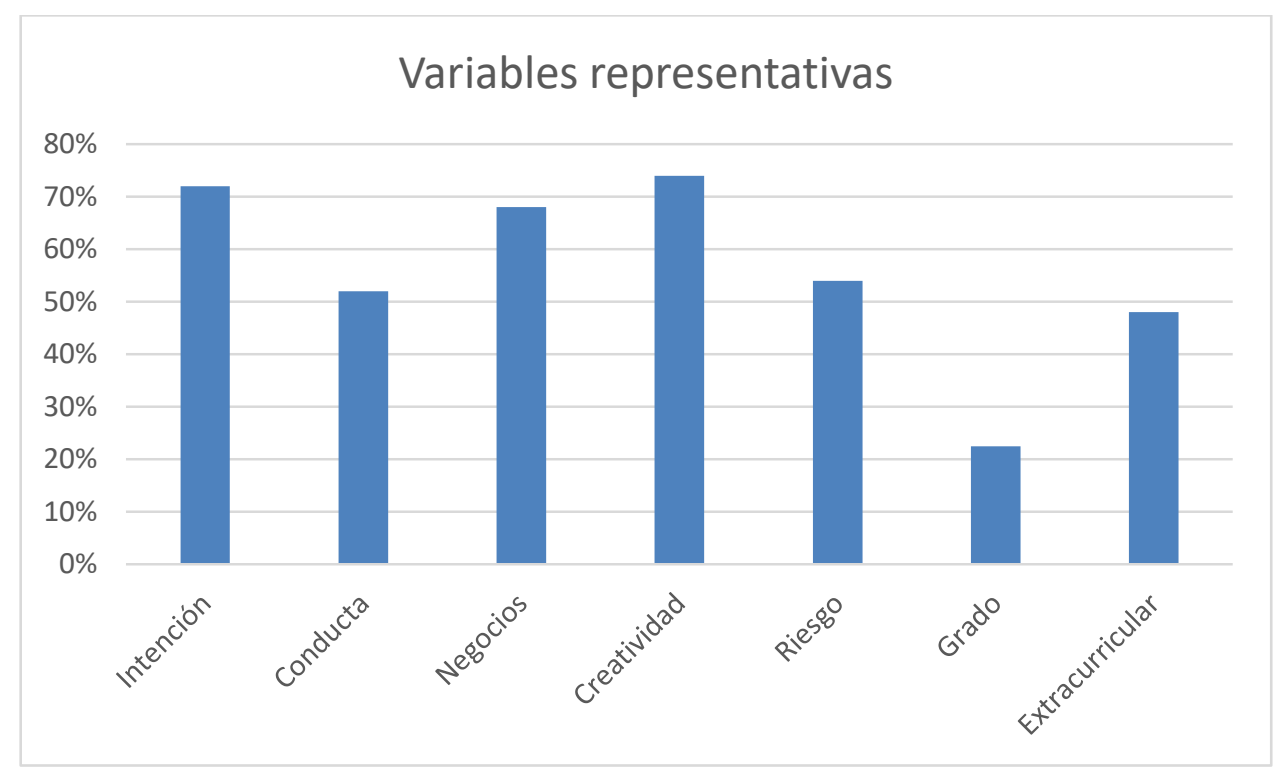

Fuente: Elaboración Propia

\subsection{Análisis comparativo}

Seguidamente se realiza una descripción de la vocación emprendedora del resto de los profesionales, y se realizan algunas comparaciones de interés para resaltar aquellas variables que puedan diferenciar al contador de otras profesiones.

Se muestran previamente las características de la muestra sobre las cuales se han obtenido los resultados. 
Tabla 7: Características de la muestra

\begin{tabular}{|l|r|r|}
\hline \multicolumn{1}{|c|}{ Edad } & Contadores & $\begin{array}{c}\text { No } \\
\text { contadores }\end{array}$ \\
\hline Sub 35 & $42 \%$ & $24 \%$ \\
\hline $35 / 45$ & $44 \%$ & $51 \%$ \\
\hline $46 / 55$ & $10 \%$ & $16 \%$ \\
\hline Sobre 55 & $4 \%$ & $9 \%$ \\
\hline
\end{tabular}

\begin{tabular}{|l|r|r|}
\hline \multicolumn{1}{|c|}{ Sexo } & Contadores & $\begin{array}{c}\text { No } \\
\text { contadores }\end{array}$ \\
\hline Hombres & $56 \%$ & $68 \%$ \\
\hline Mujeres & $44 \%$ & $32 \%$ \\
\hline
\end{tabular}

\begin{tabular}{|l|r|r|}
\hline \multicolumn{1}{|c|}{ Universidad } & Contadores & \multicolumn{1}{c|}{$\begin{array}{c}\text { No } \\
\text { contadores }\end{array}$} \\
\hline UNLP & $88 \%$ & $76 \%$ \\
\hline Otras & $12 \%$ & $24 \%$ \\
\hline
\end{tabular}

Fuente: Elaboración propia

Las observaciones en la muestra de contadores versus la del resto de los profesionales, determinan que las vocación emprendedora para estos últimos alcanza un valor promedio de 47,6 con una dispersión de 19,44. Es decir, cerca de 7 puntos menos pero con un menor grado de variabilidad.

Gráfico No 8: V.E. contadores y no contadores.

\section{Vocación emprendedora promedio comparativa}

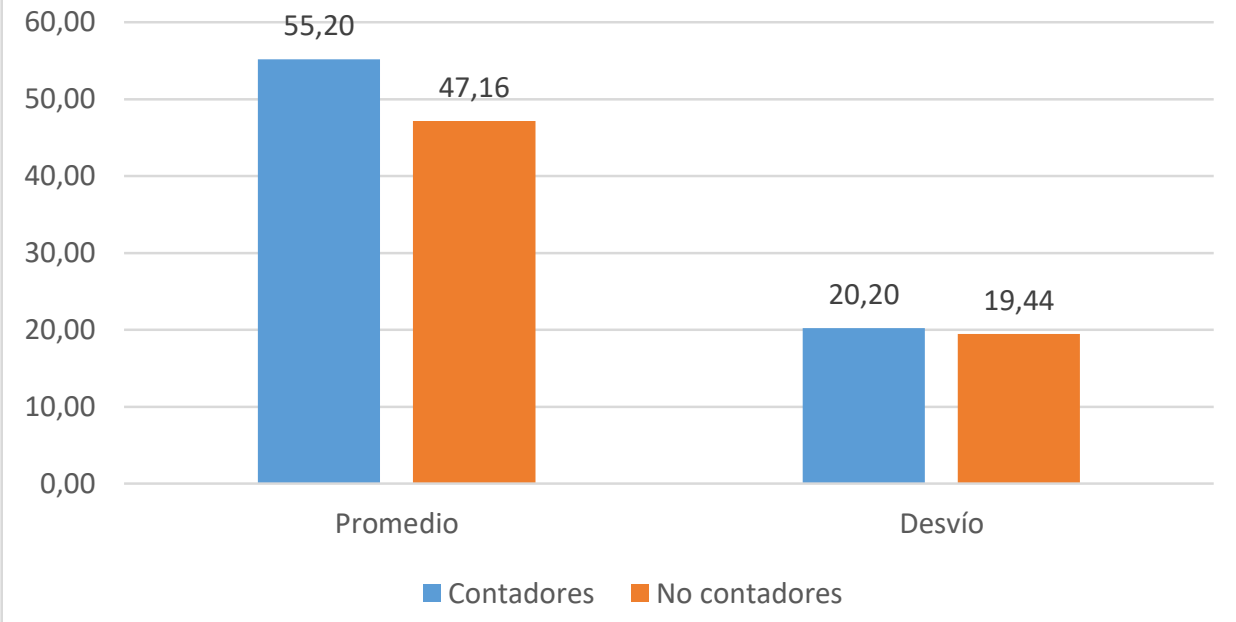

Fuente: Elaboración propia 
a) Proporción de profesionales con vocación emprendedora.

De los profesionales analizados, el $23 \%$ de ellos son considerados con un nivel de VEC bajo (inferior a 40), valor muy similar al caso de los contadores. El $72 \%$ de los encuestados, se encuentran en el tercil medio, muy por encima del $54 \%$ de los contadores, siendo que los considerados con VE alta (mayor a 70), representan solamente el $5 \%$ de ellos.

Gráfico № 9: V.E. en terciles

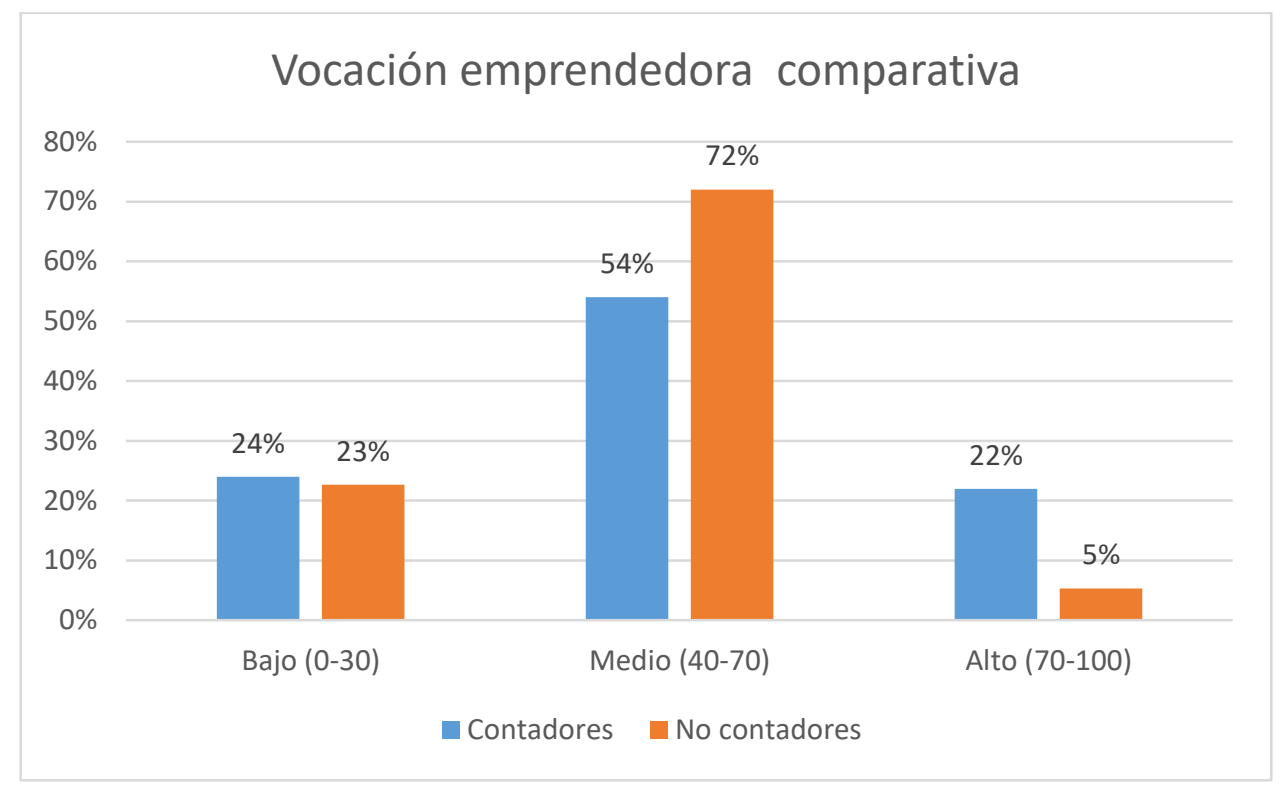

Fuente: Elaboración Propia

En la comparación dividiendo la muestra en mitades, se encuentra que la mitad poco emprendedora representa el $45 \%$, por encima del $34 \%$, del caso de los contadores. 
Gráfico Nº 10: V.E. en mitades

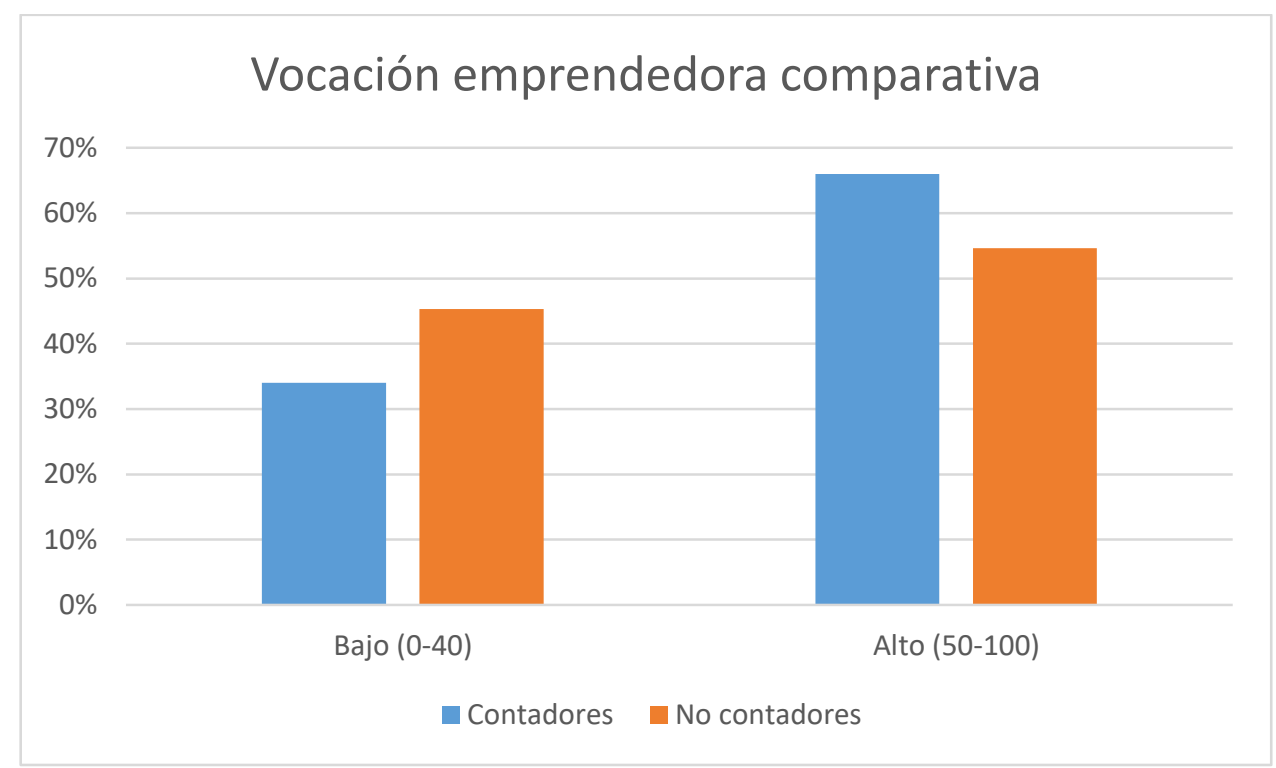

Fuente: Elaboración propia

b) Características personales.

Al analizar en detalle los factores actitudinales, instrumentales y psicológicos, se observa que existe en promedio un $15 \%$ de diferencia a favor del contador en cuanto a los factores actitudinales, siendo que la intención emprendedora y el sentimiento de ser hombre de negocios, marcan las mayores diferencias.

Gráfico № 11: Comparación de componentes entre contadores y no contadores

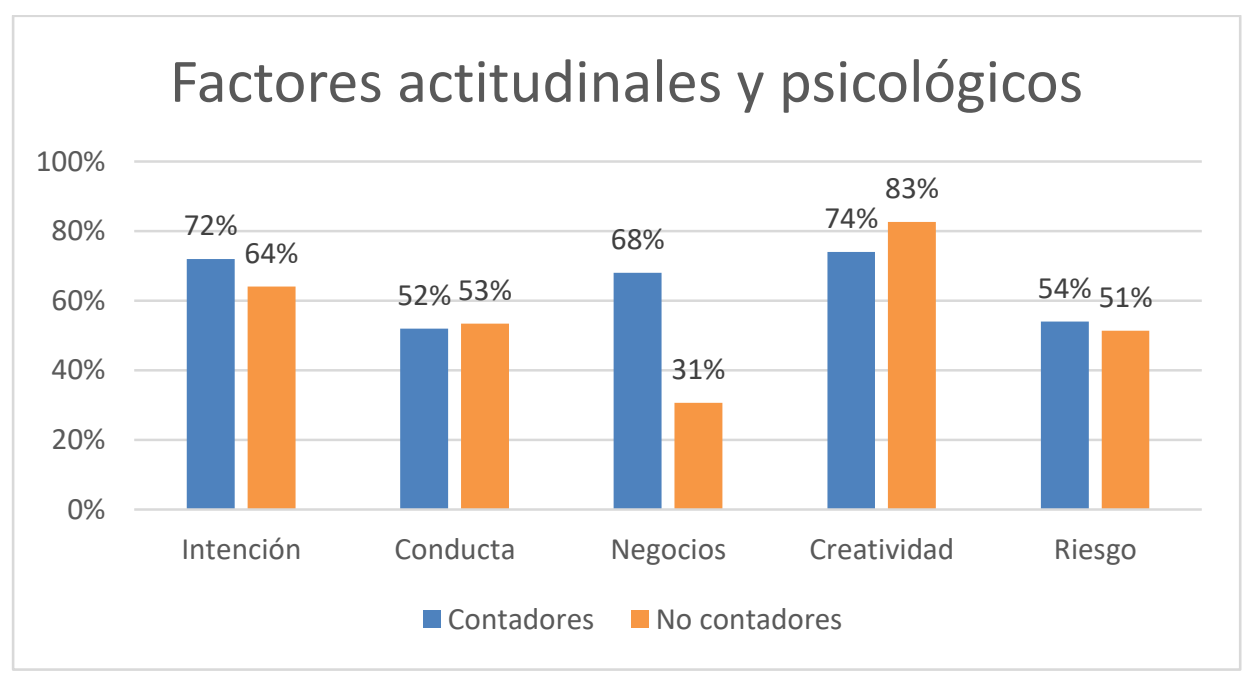

Fuente: Elaboración Propia 
En cuanto a las variables instrumentales, el $44 \%$ de los contadores perciben que la formación de grado le brinda las suficientes herramientas para el emprendimiento, mientras que en el resto de los profesionales, solo el $19 \%$ considera que ha recibido dicha formación.

Gráfico № 12: Comparación de variables herramentales de grado

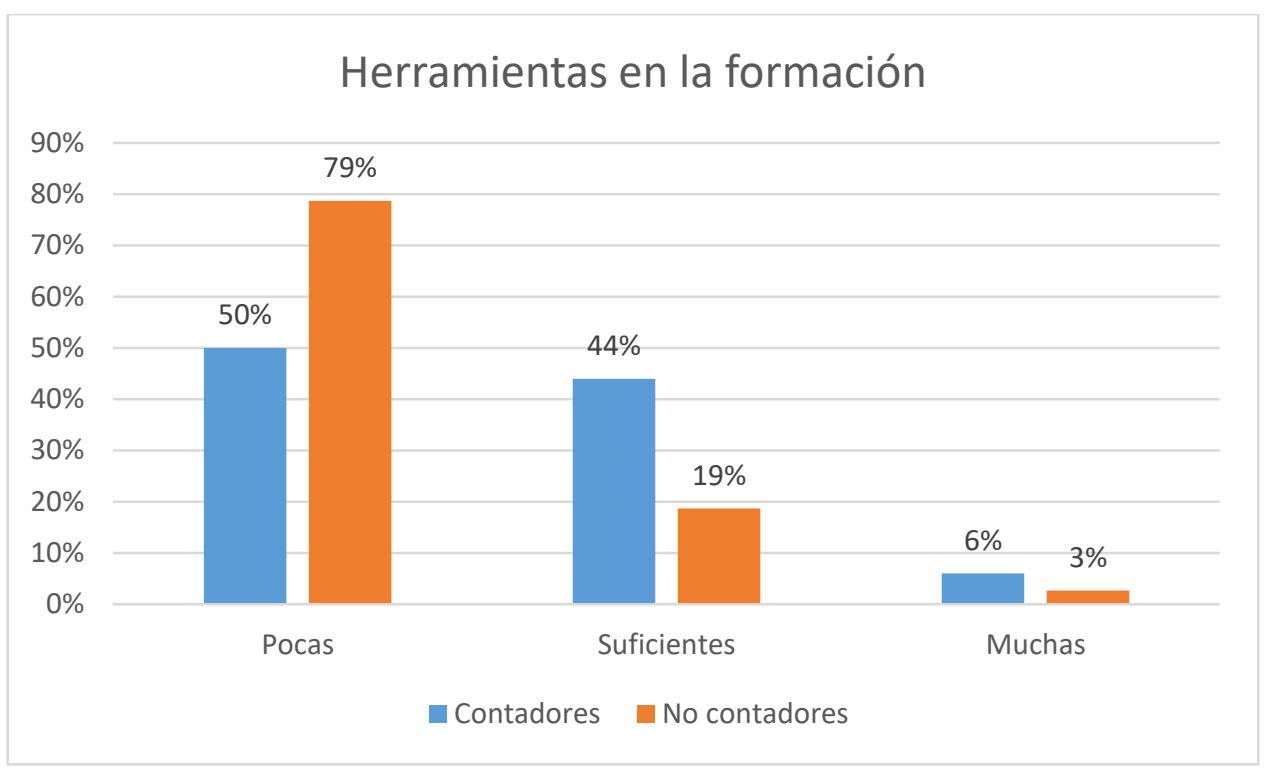

Fuente: Elaboración propia

No obstante ello, el $64 \%$ de los profesionales ha complementado la formación en negocios con cursos extracurriculares, en relación al $52 \%$ de los contadores. 
Tabla № 8: Resumen comparativo de variables

\begin{tabular}{|l|r|r|r|l|}
\hline \multicolumn{1}{|c|}{ Variables } & Contadores & $\begin{array}{c}\text { No } \\
\text { contadores }\end{array}$ & $\begin{array}{c}\text { Diferencia al } \\
\mathbf{5 \%}\end{array}$ & Resultado \\
\hline Intención & $\mathbf{7 2 \%}$ & $64 \%$ & $8 \%$ & Contador \\
\hline Conducta & $52 \%$ & $53 \%$ & $-1 \%$ & Indiferente \\
\hline Negocios & $68 \%$ & $31 \%$ & $37 \%$ & Contador \\
\hline $\begin{array}{l}\text { Promedio } \\
\text { Actitudinales }\end{array}$ & $\mathbf{6 4 \%}$ & $\mathbf{4 9 \%}$ & $\mathbf{1 5 \%}$ & Contador \\
\hline Creatividad & $\mathbf{7 4 \%}$ & $\mathbf{8 3 \%}$ & $\mathbf{- 9} \%$ & No Contador \\
\hline Riesgo & $54 \%$ & $51 \%$ & $3 \%$ & Indiferente \\
\hline $\begin{array}{l}\text { Promedio } \\
\text { Psicológicas }\end{array}$ & $\mathbf{6 4 \%}$ & $\mathbf{6 7 \%}$ & $\mathbf{- 3 \%}$ & Indiferente \\
\hline Grado & $23 \%$ & $18 \%$ & $5 \%$ & Contador \\
\hline Extracurricular & $\mathbf{4 8 \%}$ & $36 \%$ & $12 \%$ & Contador \\
\hline $\begin{array}{l}\text { Promedio } \\
\text { Instrumentales }\end{array}$ & $\mathbf{3 5 \%}$ & $\mathbf{2 7 \%}$ & $\mathbf{8 \%}$ & Contador \\
\hline
\end{tabular}

Fuente: Elaboración Propia

\subsection{Análisis complementario}

Dado que se cuenta con una muestra de 125 profesionales entre contadores y no contadores, se realiza un análisis genérico de todos los profesionales, (contadores y no contadores), que podrán ser utilizados en otros trabajos de investigación.

Si bien la cantidad de 125 profesionales puede no ser considerada representativa en términos estadísticos, el hecho de circunscribirse a profesionales platenses exclusivamente, podría ser útil para análisis de similares características a realizar en otras ciudades y establecer comparaciones en los resultados obtenidos

De esta muestra, se concluye que el puntaje medio de VE es de 50,64, con una dispersión de 21. El análisis indica que no existe diferencia significativa entre hombres y mujeres en su VE, y que la VE en el cuartil de edad comprendido entre 35 a 45 años, es de un $47 \%$, muy por debajo del resto de los cuartiles (que es del $54 \%$ en todos los casos). 
Gráfico Nº 13: Distribución de V.E. por edad

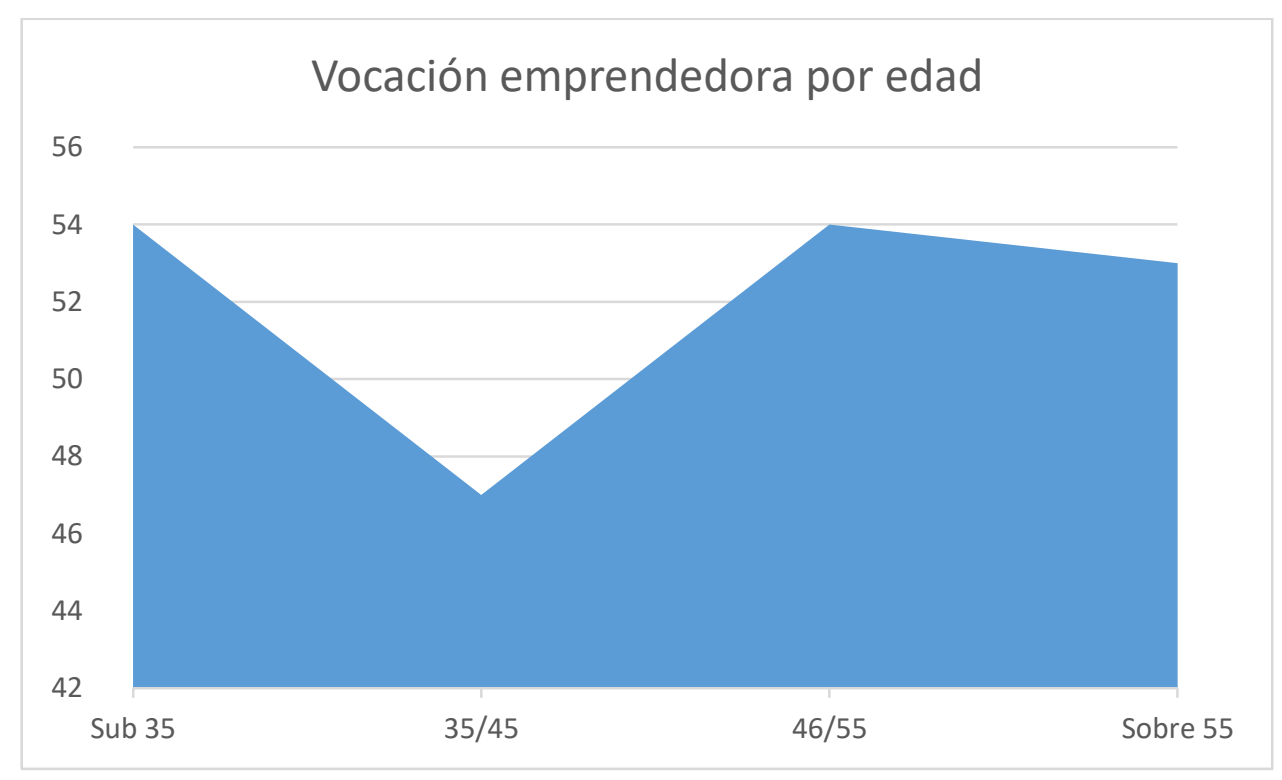

Fuente: Elaboración propia

De manera comparativa y a un mayor grado de desagregación, se pueden resumir en subconjuntos de profesiones, el nivel de V.E., siendo que el contador, luego de los ingenieros y arquitectos encuestados, se encuentran en el segundo orden de análisis, según se muestra.

Tabla 9: Ranking de V.E. por profesiones agrupadas.

\begin{tabular}{|l|c|}
\hline \multicolumn{1}{|c|}{ Profesión } & VE\% \\
\hline Ingeniería civil y arquitectura & 60,47 \\
\hline Contadores & $\mathbf{5 5 , 2 0}$ \\
\hline Lic. en economía y en administración & 52,22 \\
\hline Abogados y escribanos & 48,00 \\
\hline Médicos y odontólogos & 33,63 \\
\hline Sistemas e informática & 31,42 \\
\hline
\end{tabular}

Fuente: Elaboración propia 


\section{Conclusiones y respuestas a las preguntas de la tesis}

Como se ha podido observar existe en el contador público formado en la Universidad Nacional de La Plata, un nivel de vocación emprendedora levemente mayor al resto de las profesiones universitarias, ya que solo son superados por los profesionales de las carreras de Ingeniería y Arquitectura.

Por tal motivo, existe evidencia significativa que el contador posee mayor vocación emprendedora que el resto de las profesiones universitarias, mayoritariamente explicada por las variables actitudinales y el contenido herramental provisto por la formación de grado y posgrado. La conducta emprendedora (acciones concretas de creación de empresa) y percepción de riesgo (aversión o propensión) no son factores diferenciadores en términos significativos. (Pregunta 1)

La formación tanto de grado y la formación extracurricular, son dos de los rasgos más significativos en dicha contribución a la V.E. de los contadores. Esto se evidencia en que el doble de los contadores considera que su formación le brinda herramientas para el desarrollo de emprendimientos, siendo que incluso en los casos en que no la consideran suficiente, la mitad de ellos han tomado cursos relacionados al desarrollo de herramientas para los negocios. (Pregunta 2)

No se haya suficiente evidencia empírica como para aceptar que la formación emprendedora sea insuficiente como para justificar una capacitación adicional. Esto se basa en que de quienes percibieron como suficientes las herramientas provistas por la formación de grado, tomaron formación extracurricular en la misma proporción que quienes consideran que no la tuvieron. (Pregunta 3 )

La actitud frente al riesgo del contador no difiere del nivel de aversión al riesgo del resto de las profesiones universitarias, siendo incluso, levemente mayor 
quienes tienen alguna propensión al riesgo, no obstante en el segmento de neutralidad al riesgo, prácticamente existe coincidencia en las características de las muestras entre contadores y no contadores. Por tal motivo no se puede afirmar que el contador es adverso al riesgo y menos aún, que esa actitud lo limita en la VE. (Pregunta 4)

Al no haber un patrón de comportamiento ascendente o descendente en la VE a medida que se incrementa la edad o experiencia, no puede atribuirse a la edad el hecho de contar con una VE mayor o menor. Este análisis, para encontrar comparativamente una respuesta, se realizó también en el resto de los profesionales y se repite la misma gráfica, por lo que no existe correlación o tendencia entre edad y vocación emprendedora. Si es destacable, comprender que por algún factor que deberá investigarse, en la edad de maduración de las profesiones, la vocación emprendedora disminuye sustancialmente. (Pregunta 5)

Como conclusión generalizada, y en base a los datos analizados de las muestras entre profesionales y no profesionales, se puede afirmar que el contador cuenta con un nivel de formación (ya sea de grado y/o complementada con formación extracurricular), mediante la cual logra un cúmulo de conocimientos muy superior por sobre los manifestados por el resto de los profesionales.

No obstante ese diferencial obtenido por las características de tipo instrumental, el contador carece de características actitudinales en cuanto a la conducta emprendedora, además de que el perfil psicológico del contador relacionado a la creatividad y la innovación, es el que más lo limita en su formación y en su perfil.

A modo de aclaración se debe resaltar que dichas conclusiones solo pueden ser adjudicadas a este caso de estudio y de ninguna manera debería extrapolarse a toda la población de contadores públicos. 


\section{Reflexión del tesista}

El ejercicio de la actividad emprendedora es tomado como un desafío por quienes pretenden vincularse por primera vez al mundo de los negocios, la innovación y la puesta en marcha de un nuevo producto o incursionar en un nuevo mercado. También es un desafío cada vez que un emprendedor decide nuevamente encarar una nueva etapa en los negocios, haciendo de ese salto de paradigmas, un hábito frecuente que lo lleva a estabilizarse en ese tipo de actividad.

Es decir, que el emprendedor, trabaja de emprendedor, ya sea que cuente con una formación profesional de grado, haya tomado cursos de posgrado, se haya capacitado eventualmente en cursos para emprendedores, o bien cuente con le experiencia y preparación que la intuición de un hombre de negocios tenga.

\section{Bibliografía}

Barilaro, L. (2016). Una propuesta de taller vertical para el desarrollo de habilidades emprendedoras. Lecturas seleccionadas del XVII Encuentro Internacional de Red Motiva, 332-339.

Bulat, T. (2015). La economía de tu vida 8va ed. Buenos Aires: El Ateneo grupo editor.

Cabello Diaz, C. (2005). Emprendedurismo dentro del ámbito universitario. Cumaná: Escuela de Administración Núcleo Sucre.

Castellani, F., \& Eduardo, L. (2014). Entrepreneurship in Latin America-A step up the social ladder? Wasshington DC: Inter-American development Bank and World Bank.

Correa Correa, Z., Delgado Hurtado, C., \& Conde Cardona, Y. A. (2005). Formación en emprendimiento en estudiantes de la carrera de administración de empresas en la Universidad Pública de Popayán, Colmbia. Revista escuela Administración de negocios, 12-51.

Escolar Llamazares, C., palmero Cámara, c., \& Luis Rico, I. (2015). Jóvenes y Espíritu emprendedor; Autoeficacia, motivación y procesos psicológicos. INFAD revista de Psicología no 1 Vol 2, 151-162. 
Escudero Muñoz, J. (2008). Las competencias profesionales y la formación universitaria: posibilidades y riesgos. Revista de docencia Universitaria, No 1.

Fernandez Salinero, C., \& de la Riva, B. (2014). Mentalidad emprendedora y cultura del emprendimiento. (ELSEVIER, Ed.) Procedia-Social Behavorial Sciences, 137-143.

Fuentelsaz, L., \& Gonzalez, C. (2015). El fracaso emprendedor a través de las instituciones y la calidad del emprendimiento. Universia Business Review, 64-80.

Galindo, R., \& Echavarría, M. V. (2011). Diagnóstico de la cultura emprendedora en la escuela de ingeniería de Antioquía. Revista EIA, 8594.

García Cabrera, A. M., Deniz Deniz, M., García Soto, M., \& Martin Santana, J. (2014). ¿Los títulos de administración de empresas adaptados al EEES forman directivos emprendedores? Sociedad Española de Pedagogía, 75-92.

García, A. J., \& Gomez Scavino, M. y. (2013). "Curso de Organización Profesional. Guía de estudios para los alumnos de la Carrera de Contador Público". Colección $60^{\circ}$ Aniversario. La PLata: EDULP.

Gennero de Rearte, A., Liseras, N., Graña, F., \& Baltar, F. (2006). Los graduados universitarios y la generación de emprendimientos innovadores. Mar del Plata: Facultad de Ciencias Económicas-UNMDP.

Ghersa, J. H. (2008). Haciendo Empresas 1ra ed. San Luis: Ed. Macchi San Luis.

Gomez Vallejo, M., \& Satizabal Parra, K. (2011). Educación en emprendimiento: fortalecimiento de competencias emprendedoras en la Univerisdad Javeriana. Economía Gestión y desarrollo No 11, 121-151.

Graña, F., \& Liseras, N. (2005). Creación de empresas y universidad en Argentina:un estudio de caso. Tecnología en marcha. Volumen 18/3, 1236.

Grañal, F. M. (2002). Creación de Empresas: Factores asociados al éxito emprendedor. Mar del Plata: Universidad Nacional de Mar del Plata Editorial Martín. 
Kantis, H., Postigo, S., Federico, J., \& Tamborini, M. (2003). El surgimiento de emprendedores de base universitaria: ¿En que se diferencian? Littec.

Kastika, E. (2001). Desorganización Creativa, Organización Innovadora. Buenos Ires: Ed. Macchi.

Kastika, E. (2004). Introducción a la creatividad. . Buenos Aires: Ed. INNOVAR.

Kirby, D. (2004). Entrepreneurship Education and Incubators: pre-Incubators, Incubators and Science Parks as Enterprise Laboratories. Napoli: 14th Annual IntEnt Conference.

Kiyosaki, R. (2003). Padre Rico, Padre Pobre Novena reimpresión. Buenos Aires: Time \& MoneyNetworks Editions.

Liseras, N., \& Gennero de Rearte, A. (2015). Incidencia de las características de la facultad sobre la probabilidad de que un alumno universitario posea vocación emprendedora. Mar del Plata: Facultad de Ciencias Económicas de la Universidad Nacional de Mar del Plata.

Liseras, N., Gennero de Rearte, A., \& Graña, F. (2003). Factores asociados a la vocación emprendedora en alumnos universitarios. Mar del Plata: Facultad de Ciencias Económicas-UNMDP.

Litwin, E. (2006). El oficio de enseñar. Condiciones y contextos 1ra edición, 2da reimpresión. Buenos Aires: Paidós.

Losada, J. V. (2015). www.escuelainternacionaldecoaching.com. Recuperado el Diciembre de 2016

Pertuz Peralta, V. P., Rojas Caicedo, G. Y., Navarro Rodriguez, A., \& Quintero, L. T. (2015). Perfil docente y fomento de la cultura del emprendimiento: búsqueda de una relación. Revista Educación y Educadores, 29-45.

Platafox de Anda, G. (2002). La creatividad y la innovación en la empresa. Hospitalidad-ESDAI, 95-103.

Pozo, J. I., \& Perez Echevarría, M. (2009). Psicología del aprendizaje universitario: la formación de competencias. Madrid: Ediciones Morata.

Sanchez Tovar, Y., García fernandez, F., \& Mendoza Flores, J. E. (2015). La capacidad de innovación y su relación con el emprendimiento. Estudios Gerenciales, 243-252.

Sarasvathy, S. (2011). What makes entrepreneurs entrepreneurial? Recuperado el 27 de 12 de 2016, de www.effectuation.org: 
http://www.effectuation.org/sites/default/files/research_papers/whatmakes-entrepreneurs-entrepreneurial-sarasvathy_0.pdf

Senge, P. (2011). La quinta disciplina. Granica.

Serra, R. (2000). El nuevo juego de los negocios. BUenos Aires: Norma.

Trías de Bes, F. (2007). El libro negro del emprendedor. Buenos Aires: Empresa Activa.

Verástegui, J., \& Farías Martinez, M. (2012). Perfil y prácticas educativas del docente orientado a la innovación en las escuelas de negocios en México. (UNIVERSIA, Ed.) Revista Interamericana de Educación Superior (RIES), 117-127. 


\section{Anexo: Encuesta (modelo)}

\section{Encuesta profesional emprendedor}

Para ser completada por graduado de contador, esté o no esté matriculado o ejerciendo la profesión.

Dirección de email *

Datos Personales y Profesionales

Solamente serán utilizados de modo estadístico para investigación académica Edad *

C. hasta 35 años

(c) $36-45$

C $46-55$

C más de 55

Sexo *

C Hombre

C. Mujer

¿Cuánto hace que se graduó? *

(C) menos de 2 años

C de 2 a 5 años

C 5 a 10 años

C. más de 10 años

Facultad de la que egresó *

(C) UNLP

O Otras universidades privadas

Otras universidades públicas

Propósito y conducta emprendedora

¿Tiene proyectado en algún momento de su vida crear su propia empresa? (solo o asociado). Sin considerar al estudio profesional como empresa. *

C Si

C No

¿Participa o ha participado en algún momento en la creación de alguna empresa, sin importar su dimensión o el éxito alcanzado? *

C Si

(C) No 
Perfil de emprendedor

¿Considera Ud. que es creativo o innovador en algún aspecto de su vida y/o profesión? *

C Si

C No

Con respecto al riesgo y los negocios. ¿Cómo se considera? *

C Cercano al riesgo

El estrictamente necesario

C Prefiero no asumir riesgos

¿Se considera un hombre/mujer de negocios? *

C SI

C No

Formación emprendedora

¿Considera Ud. que ha recibido herramientas para el desarrollo de emprendimientos en su formación universitaria? *

C Pocas/Ninguna herramientas

Las suficientes

C. Muchas herramientas

¿Ha tomado cursos fuera del ámbito académico vinculados a la actividad empresarial? *

C Si

C No 